\title{
Cooling of cultured water can resist heart failure caused by collagen deposition and necrosis of cardiac fibers under chronic heat stress in sturgeon
}

\section{Chaoyang Zhang}

Sichuan Agricultural University

\section{Miao Zhang}

Sichuan Agricultural University

\section{Zihan Xu}

Sichuan Agricultural University

\section{Datian Li}

Sichuan Agricultural University

\section{Quan Gong}

Sichuan Academy of Agricultural Sciences

\section{Xiaoli Huang}

Sichuan Agricultural University

Jiayun Wu

Sichuan Agricultural University

Zhi He

Sichuan Agricultural University

\section{Xiaogang Du}

Sichuan Agricultural University

\section{Defang Chen}

Sichuan Agricultural University

Jun Jiang

Sichuan Agricultural University

Jun Du

Sichuan Agricultural University

Shiyong Yang ( $\nabla$ yangshiyong@sicau.edu.cn )

Sichuan Agricultural University

\section{Research}

Keywords: Cooling of cultured water, chronic heat stress, Acipenser baerii, heart failure, myocardial fibrotic, myocardial necrosis 
Posted Date: November 11th, 2021

DOI: https://doi.org/10.21203/rs.3.rs-1054837/v1

License: (c) (i) This work is licensed under a Creative Commons Attribution 4.0 International License. Read Full License 


\section{Abstract \\ Background}

Chronic heat stress (CHS) may threaten the survival of cultivated and wild sturgeon by jeopardizing heart function.

\section{Methods}

Therefore, we established a heart damage model for the Siberian sturgeon (Acipenser baerii) using varying degrees of $\mathrm{CHS}\left(24^{\circ} \mathrm{C}\right.$ and $\left.28^{\circ} \mathrm{C}\right)$ to explore its effect on the heart structure and function, and their mutual relationship.

\section{Results}

Our research showed that CHS caused systemic heart failure in A. baerii, clinically manifested as severely irregular ventricles, increased myocardial fibrotic in the interstitium of cardiomyocytes, and myocardial necrosis. Echocardiographic imaging of $A$. baerii revealed an accelerated heart rate, incomplete ventricular contraction, decreased cardiac output, and significantly reduced pumping efficiency under CHS. Generally, the contractility of the heart decreased and the afterload increased under CHS, which is typical of high-resistance and low-output heart failure. However, cooling of cultured water $\left(20^{\circ} \mathrm{C}\right) \mathrm{can}$ offset the adverse effects of partial or total CHS on tissue structure and function.

\section{Conclusion}

Our results systematically characterized the relationship between the effects of CHS on the heart structure and heart function in sturgeon. This work provides a preliminary reference for future summer breeding pond management and protection of sturgeon.

\section{Introduction}

Global warming and the construction of river dams can cause the water temperature of rivers to increase for extended periods of time which threatens the survival of aquatic organisms [1-6]. Chronic heat stress (CHS) occurs when the environmental temperature exceeds the optimal temperature range for fish to survive for a long-term [7-10]. CHS can directly threaten the physiological stability of freshwater species, affecting their behavior, growth, development, reproduction, immune, digestion, and circulatory system, and can even cause death [11-16].

Acipenser baerii is widely distributed in important economic fish in the northern hemisphere, and the caviar produced by adult fish has extremely high nutritional value [17-20]. Sichuan Province's sturgeon 
farming production ranks among the top in China, and its normal growth temperature of sturgeon is maintained at $5-20^{\circ} \mathrm{C}$ all year round (Data form Sichuan Runzhao Fishery Co., Ltd). However, in summer, the water temperature of sturgeon breeding ponds often increases suddenly and lasts for 9-12 days, causing the $\mathrm{CHS}$ and a large number of deaths of cultured sturgeons. Mai et al. found that the growth of A. baerii was significantly hindered when the feeding water temperature was maintained at $24^{\circ} \mathrm{C}$, and the survival rate at $27^{\circ} \mathrm{C}$ was significantly reduced [21]. Our team's CHS experiments show that the survival of A.baerii decreases when the water temperature exceeds $20^{\circ} \mathrm{C}$ (Yang et al. 2021). In the process of growth and development, the normal maintenance of heart function is essential to ensuring normal growth, development, and reproductive behavior [22]. Heart, the life-sustaining organ of fish, generates pressure to circulate the blood, transport oxygen from fish gills to various tissues, and remove metabolic waste products, thereby supporting active biological processes [23]. Therefore, the normal physiological temperature of the heart is the prerequisite for maintaining the high production efficiency of sturgeon. In recent years, an increasing number of studies have examined the effects of heat stress on sturgeon $[6,14$, 24]. However, few have examined the effect of $\mathrm{CHS}$ on the sturgeon heart and establish the relationship between heart structure and function.

Tissue blood perfusion requires rhythmic and periodic contraction and relaxation of the heart ventricles and complete cardiomyocyte support. Among them, the changes in ECM (extracellular matrix), led by fibrillar collagen composition, play an important role in affecting the heart movement of fish[25]. Fibrillar collagen is the most common structural fibres in the ECM. The fibrillar collagen forms stiff fibres that maintain and support the alignment of myocardial cells by bearing wall stress[26, 27]. However, excessive deposition of cardiac collagen will increase the passive stiffness of the chamber wall and reduce the chamber compliance and dilatability of the ventricular cavity, which can have implications for diastolic filling[28]. However, changes in the composition of myocardial collagen in the heart of $A$. baerii under heat stress and the relationship between the composition of myocardial collagen and changes in cardiac function need to be further studied.

Moreover, pumping blood is considered the main function of the heart, its performance can affect fish behavior, as well as changes in organs, tissues, and cells (intercellular stroma) [15, 29-31]. However, adverse and extreme external pressure stress may cause damage to the structure of myocardial cells and cause necrosis [32]. This is particularly concerning because most fish hearts lack coronary circulation and only receive oxygen via diffusion from the venous return. Unlike the spongy layer, which receives venous blood, the compact layer of the fish ventricle has a coronary blood supply from the gill [33]. However, heat stress can cause serious damage to the gill tissue of fish, decrease in oxygen exchange capacity, and severely damage the oxygen supply to the heart [34]. For fish, the thickness and structural integrity of the dense layer of the ventricle are important prerequisites for maintaining the pumping function of the heart $[35,36]$. This heart organ organization can impose limits on sustaining cardiac function at different temperatures and may lead to myocardial cell necrosis[37]. However, the influence of A. baerii myocardial necrosis under $\mathrm{CHS}$ on cardiac structure and the relationship between myocardial necrosis and changes in cardiac function need further research. 
In present study, we systematically investigated the behavior of sturgeon under $\mathrm{CHS}$, as well as the structure, function and molecular regulatory pathway of heart tissue. we applied echocardiographic techniques and transcriptomics analysis to detect changes in cardiac function indicators in sturgeon to further establish the link between heart tissue structure and pumping function under $\mathrm{CHS}$. Meanwhile, the counteracting effect of aquaculture water cooling on CHS was systematically tested. Our research has established a foundation for the connection between heart structure and function in sturgeon under $\mathrm{CHS}$ and provides a reference for the protection of wild and farmed cold-water fish.

\section{Materials And Methods}

\section{Fish maintenance}

All animal handling procedures were approved by the animal care and use committee of Sichuan Agricultural University in accordance with the animal experiment guidelines under license NO. ZCY2019202031. 400 healthy $A$. baerii of similar weights $(84.531 \pm 2.713 \mathrm{~g})$ and body lengths $(31.491 \pm$ $1.746 \mathrm{~cm}$ ) were purchased from Sichuan Runzhao Fishery Co., Ltd. China. The fish were held in tanks under a $12 \mathrm{~h}$ light : dark cycle with an uninterrupted oxygen supply to ensure dissolved oxygen remained above $7.5 \mathrm{mg} / \mathrm{L}$. The water in the tanks was pretreated with UV light and an aeration process, and $20 \%$ of the culture water was renewed every day. The $\mathrm{pH}$ ranged between 7-8 and ammoniacal nitrogen and nitrite were maintained at $0-0.015 \mathrm{mg} / \mathrm{L}$. The fish were fed with $1 \%$ of the fish body weight of commercial feed three times daily. Eventually, fish that were responsive, robust, and healthy were selected for experimentation.

\section{Experimental treatment}

According to the study by Yang et al., (in 2021) A. baerii exhibits significant increases in fatality and organ damage when the breeding water temperature reaches $28^{\circ} \mathrm{C}[14]$. Based on the observations, the sturgeon in this experiment were divided among three groups to simulate normal and CHS conditions: a control group at $20^{\circ} \mathrm{C}(\mathrm{C})$ and two elevated temperature groups at $24^{\circ} \mathrm{C}(\mathrm{M})$ and $28^{\circ} \mathrm{C}(\mathrm{H})$. A total of 180 fish were randomly assigned to the three treatments, with each group consisting of four parallel tanks holding $15 \mathrm{fish}$ each. For the control group, the sturgeon were raised at normal room temperature $\left(20^{\circ} \mathrm{C}\right)$ for the duration of the experiment. The $\mathrm{CHS}$ groups were also held at room temperature for the first 14 days. Then, according to the heating scheme (Supplementary table 1), the temperatures in the stressed groups were increased by $1^{\circ} \mathrm{C} / \mathrm{d}$ until reaching the experimental temperatures on day 22 . The $\mathrm{CHS}$ temperatures were maintained until day 34 (heat stress exposure of 12 days). Immediately following, the water temperatures of the $\mathrm{M}$ and $\mathrm{H}$ groups were adjusted to $20^{\circ} \mathrm{C}$ for one week to allow for recovery (Supplementary table 1).

On day 35, 10 sturgeon were randomly selected from each group for sampling. Collect tail vein blood samples $(n=5)$ for myocardial enzyme leakage detection, and cardiac tissue for transcriptomics $(n=3)$ analysis. Fish from the recovery groups (R-M and R-M) were sampled as before on day 42 . 


\section{Heart disease activity index (HDAl) evaluation}

Based on the symptoms the sturgeon in the farm experienced in summer, we established a novel heart disease activity index ( $\mathrm{HDAl}$ ) with reference to the research by Chen et al. The index was designed to evaluate the "heart failure-like" behavior in A. baerii under CHS (Table 1) [38, 39]. Similar to the above experimental treatments (Section 2.2). The procedure was designed to assess the degree of damage to the $A$. baerii after experiment CHS. The monitored variables included feeding rate, swimming speed, imbalance rate, respiratory rate, cardiac color, and percentage of ventricular injury, and all variables were blind scored by two trained researchers. The evaluation experiment included $\mathrm{CHS}$ treatment and a recovery period. 
Table 1

Scoring system of HDAl for sturgeon.

\begin{tabular}{|c|c|c|}
\hline Features graded & Description & Score \\
\hline \multirow[t]{3}{*}{ Feeding rate $(n=3)$} & $0.7 \%-1 \%$ (Containing $0.7 \%)$ & 0 \\
\hline & $0.3 \%-0.7 \%$ (Containing $0.3 \%)$ & 1 \\
\hline & $0-0.3 \%$ & 2 \\
\hline \multirow[t]{3}{*}{ Swimming speed $(n=6)$} & Normal ( $\leq 12 \mathrm{~cm} / \mathrm{s})$ & 0 \\
\hline & Mild fast (12 - $16 \mathrm{~cm} / \mathrm{s})$ & 1 \\
\hline & Speediness ( $\geq 16 \mathrm{~cm} / \mathrm{s}$ ) & 2 \\
\hline \multirow[t]{3}{*}{ Imbalance rate } & $\begin{array}{l}\text { Less than } 5 \% \text { of the total number of experimental } \\
\text { fish }\end{array}$ & 0 \\
\hline & $5-15 \%$ of the total number of experimental fish & 1 \\
\hline & $\begin{array}{l}\text { More than } 15 \% \text { of the total number of experimental } \\
\text { fish }\end{array}$ & 2 \\
\hline \multirow[t]{3}{*}{ Respiratory rate $(n=6)$} & Normal ( $\leq 70 / \mathrm{min})$ & 0 \\
\hline & Mild (70 - 90 /min) & 1 \\
\hline & Severe ( $\geq 90 / \mathrm{min})$ & 2 \\
\hline \multirow[t]{3}{*}{ Cardiac color $(n=3)$} & Normal & 0 \\
\hline & Slightly black heart color & 1 \\
\hline & Severe darkening of the heart & 2 \\
\hline \multirow{5}{*}{$\begin{array}{l}\text { Percentage of ventricular injury }(n= \\
\text { 3) }\end{array}$} & 0 & 0 \\
\hline & $1-25 \%$ & 1 \\
\hline & $26-50 \%$ & 2 \\
\hline & $51-75 \%$ & 3 \\
\hline & $76-100 \%$ & 4 \\
\hline
\end{tabular}

Feeding rate $=$ total feed intake $(\mathrm{g}) /$ total body weight $(\mathrm{g}) \times 0.01 \times 100 \%$. To ensure measured swimming speed sturgeon are not subject to mechanical equipment and environmental impact. We used the camera to randomly record the swimming trajectory (curved or straight) and time of the horizontal sturgeon in the treatment tank one hour before feeding. Swimming speed = Swimming distance (cm) / time (s). Imbalance rate $=$ number of lateral flip $/$ total number. Meanwhile, the sturgeon was recorded for 5 minutes continuously one hour before feeding during the experiment. Six sturgeons in each group were randomly selected for respiration frequency statistics. Respiratory rate $(T / \mathrm{min})=$ number of operculum 
opening and closing cycles / time ( $\mathrm{min})$. Sensory score for the color of the dissected sturgeon heart $(\mathrm{n}=$ 3 ), then the hearts were dissected from sturgeon in each treatment and fixed in $4 \%$ paraformaldehyde overnight at room temperature. Paraffin sections were prepared and stained with haematoxylin and eosin

( $H \&$ E). Sections were photographed under a light microscope (Nikon, Tokyo, Japan). The obtained heart histopathological images were analyzed using Image J 1.35a (National Institutes of Health, USA) image analysis software. Percentage of ventricular injury = ventricular injury area / total cross-sectional area of ventricle $\times 100 \%$. Scoring system of HDAl for sturgeon can be seen in Table $1(n \geq 3)$.

\section{Myocardial enzyme determination}

Myocardial enzyme is a biomarker of myocardial injury used to monitor the degree of myocardial necrosis $[40,41]$. To further determine whether myocardial cells were necrotic, the content of myocardial enzymes in the plasma was measured. The myocardial enzyme leakage activity indexes for plasma were determined using diagnostic kits produced by Nan Jing Jian Cheng Bioengineering Institute (Nanjing, China) following the manufacturer's instructions. The blood from each sample was centrifuged at $3500 \mathrm{~g}$ $10 \mathrm{~min}$ at $4^{\circ} \mathrm{C}$. The diagnostic kits used in this experiment measured LDH (lactate dehydrogenase) (A0202-2), AST (aspartate aminotransferase) (C010-2-1), and CK (creatine kinase) (A032-1-1).

\section{Echocardiography and histopathological examination}

A modified version of the echocardiographic detection methods of Sun et al., Fang et al., and Liu et al. was used [42-44]. The sturgeon conducts the same time and treatment experiment as in section 2.2. Five sturgeon from each group (day 35 and 42) were randomly selected from the surviving pool of fish for echocardiographic analysis. Each selected fish was anaesthetized in $100 \mathrm{mg} / \mathrm{L}$ MS-222 (Sigma, USA) until loss of equilibrium, and placed ventral side up in a small sponge holder submerged in a transparent plastic bracket filled with water (water temperature corresponds to treatment temperature) from their respective aquaria. The ultrasound transducer (CHISON, China) was positioned on the ventral side of the sturgeon. Both the longitudinal and short axes of the CHISON Qbit 5VET Ultrasonic Diagnostic System (CHISON, China) were used during imaging. The frequency for B-mode imaging (Brightness-mode Ultrasound imaging) was $10 \mathrm{MHz}$ and a typical sample of B-mode video of sturgeon has been provided in Supplementary Video 1. The frequencies of color Doppler and pulsed-wave Doppler were $6.5 \mathrm{MHz}$, presented in Supplementary Video 2. Assessments were performed so that the operators were 'blinded' to eliminate the potential for operator bias. Assessments were conducted in conditions temperature corresponding to the treatment temperature of the sturgeon for $<5 \mathrm{~min}$, allowing echocardiographic recordings of at least three cardiac cycles. The water environment during the detection process and the indoor temperature during the detection are the corresponding experimental treatment temperatures.

With the help of the color-Doppler mode, sampling windows of pulsed-wave Doppler were positioned at the atrioventricular valve (AV), bulboventricular valve (BV), abdominal aorta (AA), and between the two valves. Clear images were captured and the Cardiac Software Package (CHISON, China) was used to analyze the relevant parameters. The pulsed-wave Doppler velocity measurement was taken from a 
position as parallel to the blood flow as possible. The angle was adjusted if necessary, but adjustments were limited to a maximum of 15 degrees.

Basic parameters, such as body weight (BW), carcass weight (CW), full length ( $F L)$, and body length (BL) were measured promptly after echocardiographic examinations. Ratios of ventricular and heart mass to $\mathrm{BW}$ or $\mathrm{CW}$ were chosen to assess changes in cardiac morphology. Dissected tissues were immediately fixed in $10 \%$ neutral-buffered formalin for histopathologic examination. The samples were trimmed, dehydrated, and embedded in paraffin wax before sectioning at $4 \mu \mathrm{m}$ for $\mathrm{H} \& \mathrm{E}$ and Masson trichrome staining. Images were recorded on a light microscope (Nikon, Tokyo, Japan). The degrees of change in fibrillar collagen content, atrophy, infiltration, necrosis, hyperplasia of fat, and blurred epicardial border in the heart were evaluated according to Huang et al [45]. Every change was assessed with a score (S) ranging from 0 to 6 depending on the degree of change: (0) unchanged, (2) mild change, (4) moderate change, and (6) severe change (diffuse lesion).

The obtained histopathological images were analyzed using Image J 1.35a (National Institutes of Health, USA) image analysis software. The basic calculation was conducted as follows: ventricle stratum spongiosum myocardial density $(\%)=$ pixels (area of myocardium) / pixels (total area of ventricle) $\times 100 \%$; fibrillar collagen content in the myocardium of the stratum spongiosum $=$ pixels (area of myocardial collagen) / pixels (total area of ventricle stratum spongiosum) $\times 100 \%$.

\section{Echocardiographic image data analysis}

Clear echocardiographic images were obtained and offline analyses were performed. With reference to the analysis process established by Fang et al., [42], the measurement results were analyzed as follows. The epicardial border was outlined using the Cardiac Function Measurement Package (CHISON, China) and the end-diastolic (E-d) and end-systolic (E-s) ventricular areas (A) were calculated (Fig. 1). The diameter of the AV valve annulus during systole (D) was also recorded. In addition, ventricular filling (atrioventricular flow) and ejection flow (BV flow) were also measured (Fig. 1). Corresponding parameters such as peak velocity, mean velocity, and velocity time integral (VTI) can be automatically calculated when using the continuous wave Doppler mode. The calculated formulas-cross-sectional area (CSA) was used to evaluate stroke volume $(\mathrm{SV}, \mu \mathrm{L})$, cardiac output $(\mathrm{CO}=\mathrm{SV} * \mathrm{HR})$, and pulsatility index $(\mathrm{PI}=$ ventricular blood flow peak systole / end-diastolic trough). SV was calculated as CSA $\times$ VTI. Defining CSA as $\pi D^{2} / 4$, the VTI of the BV valve was measured using pulsed Doppler. The pulsed Doppler image was used to estimate ventricular ejection time (VET) by measuring the time of ventricle ejection from start to finish (Fig. 1).

\section{RNA-seq}

\subsubsection{RNA extraction, library preparation and illumina sequencing}


The heart in sturgeon in different treatment group were selected for RNA-seq, each group including three replicates. Total RNA was extracted from the tissue using TRIzol ${ }^{\circledR}$ Reagent according the manufacturer's instructions(Invitrogen). Then RNA quality was determined using 2100 Bioanalyser (Agilent) and quantified using the ND-2000 (NanoDrop Technologies). High-quality RNA sample (OD260/280=1.8 2.2, OD $260 / 230 \geq 2.0, R I N \geq 6.5,28 S: 18 S \geq 1.0,>10 \mu \mathrm{g}$ ) was used to construct sequencing library.

RNA-seq transcriptome libraries were prepared following TruSeqTM RNA sample preparation Kit from Illumina (San Diego, CA), using $1 \mu \mathrm{g}$ of total RNA. Shortly, messenger RNA was isolated with polyA selection by oligo(dT) beads and fragmented using fragmentation buffer. cDNA synthesis, end repair, Abase addition and ligation of the Illumina-indexed adaptors were performed according to Illumina's protocol. Libraries were then size selected for cDNA target fragments of 200-300 bp on 2\% Low Range Ultra Agarose followed by PCR amplified using Phusion DNA polymerase (NEB) for 15 PCR cycles. After quantified by TBS380, Paired-end libraries were sequenced by Illumina NovaSeq 6000 sequencing (150bp*2, Shanghai BIOZERON Co., Ltd ).

\subsubsection{De novo assembly and annotation}

The raw paired end reads were trimmed and quality controlled by Trimmomatic with parameters (SLIDINGWINDOW:4:15 MINLEN:75) (version 0.36

http://www.usadellab.org/cms/uploads/supplementary/Trimmomatic).Then clean data from all samples were used to do RNA de novo assembly with Trinity (http://trinityrnaseq.sourceforge.net/). All the assembled transcripts were searched against the NCBI protein nonredundant (NR), String, and KEGG databases using BLASTX to identify the proteins that had the highest sequence similarity with the given transcripts to retrieve their function annotations and a typical cut-off E-values less than $1.0 \times 10^{-5}$ was set. BLAST2GO (http://www.blast2go.com/b2ghome) program was used to get GO annotations of unique assembled transcripts for describing biological processes, molecular functions and cellular components. Metabolic pathway analysis was performed using the Kyoto Encyclopedia of Genes and Genomes (KEGG, http://www.genome.jp/kegg/).

\subsubsection{Differential expression analysis and functional enrichment}

To identify DEGs (differential expression genes) between two different samples, the expression level of each transcript was calculated. Fragments/KB/Million reads (FPKM) were used to analyze the expression levels of differential genes. RSEM (http://deweylab.biostat.wisc.edu/rsem/) was used to quantify gene and isoform abundances. R statistical package software EdgeR (Empirical analysis of Digital Gene Expression in R, http://www.bioconductor.org/packages/2.12/bioc/html/edgeR.html) was utilized for differential expression analysis. Meanwhlie, functional-enrichment analysis including GO and KEGG were performed to identify which DEGs were significantly enriched in GO terms and metabolic pathways at Bonferroni-corrected P-value $\leq 0.05$ compared with the whole-transcriptome background. GO functional enrichment and KEGG pathway analysis were carried out by Goatools (https://github.com/tanghaibao/Goatools) and KOBAS (http://kobas.cbi.pku.edu.cn/home.do). 


\section{Statistical analysis}

Continuous variables were expressed as mean \pm standard deviation (SD). Categorical variables were expressed as counts and percentages. Data were analyzed using SPSS version 27. Differences between groups were assessed with one-way ANOVAs followed by post hoc analyses with Dunnett's tests. Differences between the means were considered significant or extremely significant at the $95 \%$ or $99 \%$ confidence levels $(P<0.05$ or $P<0.01)$, respectively.

\section{Results}

\section{Systemic symptoms of heart failure in A. baerii caused by CHS}

A. baerii developed relatively obvious heart failure symptoms after $\mathrm{CHS}$ treatment. Starting from day 1 to 19 , the HDAl scores of the fish in group $\mathrm{H}$ were significantly $(P<0.05$ or $P<0.01)$ higher than those of the control group (Fig. 2A). Notably, the cardiac HDAl in group $\mathrm{H}$ abruptly peaked from day 4 to day 12 , during which time it remained at a high level. Specifically, there were significant increases in feeding rate, swimming speed, imbalance rate, respiratory rate, cardiac color, and percentage of ventricular injury scores relative to the control group for most of the days between 4-12 (Fig. 2C). Fish in the heat-stressed group showed a significant recovery trend from day 18 to $19(P<0.05)$. The survival rates of the group $\mathrm{H}$ was significant lower than the control group (Fig. 2B). The survival rate dropped significantly from day 5 and continued to decrease until the end of the heat stress period. During the recovery period, there was a clear recovery trend in the $\mathrm{M}$ group, while the survival rate of the $\mathrm{H}$ group continued to decline (Fig. $2 \mathrm{~B}$ ). Generally, sturgeon in the heat stress groups showed systemic cardiopathic symptoms. In the control group, almost no deaths occurred during the experiment, no obvious pathological symptoms were observed, and the HDAl scores remained relatively stable without significant change.

\section{Significant irregular ventricular shape and heart atrophy in A. baerii caused by CHS}

Immediately after the CHS and following recovery, we performed further measurements of morphological indicators of heart condition and basic parameters of the health of $A$. baerii. Severe abnormal shapes, darkening of the ventricle, and atrophy of the heart increased with the intensity of CHS, but were partially relieved after the recovery period (Fig. 3A). Specifically, the ventricle darkening and ventricle atrophy were the most obvious with increasing CHS intensity. Next, the basic parameters were measured. All morphological indicators of the heart showed a decreasing trend with increasing intensity of CHS. The indexes related to heart weight showed significant reductions in group $\mathrm{H}$, but returned to normal levels after the recovery period. Meanwhile, there was a tendency for the ventricles to atrophy under CHS (Table 2). However, BW, CW, and BL were not significantly affected in the experimental groups (Table 2). 
Table 2

Morphological changes of $A$. baerii hearts after $\mathrm{CHS}$ and recovery..

\begin{tabular}{|c|c|c|c|c|c|}
\hline Item & C & $M$ & $\mathrm{H}$ & R-M & $\mathrm{R}-\mathrm{H}$ \\
\hline BW, g & $\begin{array}{l}86.562 \pm \\
19.520\end{array}$ & $\begin{array}{l}86.769 \pm \\
19.391\end{array}$ & $\begin{array}{l}84.692 \pm \\
15.432\end{array}$ & $\begin{array}{l}90.671 \pm \\
15.889\end{array}$ & $\begin{array}{l}90.589 \pm \\
12.751\end{array}$ \\
\hline CW, g & $\begin{array}{l}78.298 \pm \\
17.705\end{array}$ & $\begin{array}{l}78.177 \pm \\
16.924\end{array}$ & $\begin{array}{l}77.292 \pm \\
14.465\end{array}$ & $\begin{array}{l}82.208 \pm \\
15.021\end{array}$ & $\begin{array}{l}79.749 \pm \\
12.555\end{array}$ \\
\hline $\mathrm{TL}, \mathrm{cm}$ & $\begin{array}{l}32.308 \pm \\
1.645^{\mathrm{ab}}\end{array}$ & $\begin{array}{l}32.485 \pm \\
1.743^{\mathrm{ab}}\end{array}$ & $\begin{array}{l}31.954 \pm \\
1.961^{\mathrm{a}}\end{array}$ & $\begin{array}{l}33.708 \pm \\
1.850^{b}\end{array}$ & $\begin{array}{l}33.208 \pm \\
1.605^{\mathrm{ab}}\end{array}$ \\
\hline $\mathrm{BL}, \mathrm{cm}$ & $25.427 \pm 1.459$ & $\begin{array}{l}25.631 \pm \\
1.478\end{array}$ & $\begin{array}{l}25.454 \pm \\
1.616\end{array}$ & $25.715 \pm 1.208$ & $25.400 \pm 1.238$ \\
\hline$H M, g$ & $0.152 \pm 0.042^{\mathrm{ab}}$ & $0.164 \pm 0.051^{a}$ & $0.127 \pm 0.029^{b}$ & $0.157 \pm 0.039^{a b}$ & $0.170 \pm 0.057^{\mathrm{ac}}$ \\
\hline VM, g & $\begin{array}{l}0.0710 \pm \\
0.0205\end{array}$ & $\begin{array}{l}0.0782 \pm \\
0.0324\end{array}$ & $\begin{array}{l}0.0590 \pm \\
0.0124\end{array}$ & $\begin{array}{l}0.0702 \pm \\
0.0164\end{array}$ & $\begin{array}{l}0.0808 \pm \\
0.0247\end{array}$ \\
\hline $\begin{array}{l}\mathrm{HM} / \\
\mathrm{CW}\end{array}$ & $\begin{array}{l}0.1938 \pm \\
0.0301^{\mathrm{ab}}\end{array}$ & $\begin{array}{l}0.2078 \pm \\
0.0336^{\mathrm{a}}\end{array}$ & $\begin{array}{l}0.1661 \pm \\
0.0288^{b}\end{array}$ & $\begin{array}{l}0.1926 \pm \\
0.0336^{\mathrm{ab}}\end{array}$ & $\begin{array}{l}0.1991 \pm \\
0.0907^{\text {ac }}\end{array}$ \\
\hline $\begin{array}{l}\mathrm{VM} / \\
\mathrm{CW}\end{array}$ & $\begin{array}{l}0.1080 \pm \\
0.0236\end{array}$ & $\begin{array}{l}0.1041 \pm \\
0.0272\end{array}$ & $\begin{array}{l}0.0879 \pm \\
0.009\end{array}$ & $\begin{array}{l}0.0953 \pm \\
0.0196\end{array}$ & $0.0957 \pm 0.012$ \\
\hline RHM & $\begin{array}{l}0.1752 \pm \\
0.0268^{\mathrm{ab}}\end{array}$ & $\begin{array}{l}0.1874 \pm \\
0.0298^{a}\end{array}$ & $\begin{array}{l}0.1513 \pm \\
0.0259^{b}\end{array}$ & $\begin{array}{l}0.1729 \pm \\
0.0307^{a b}\end{array}$ & $\begin{array}{l}0.1752 \pm \\
0.0813^{\mathrm{ac}}\end{array}$ \\
\hline RVM & $\begin{array}{l}0.0966 \pm \\
0.0211\end{array}$ & $\begin{array}{l}0.0938 \pm \\
0.0239\end{array}$ & $\begin{array}{l}0.0798 \pm \\
0.0087\end{array}$ & $\begin{array}{l}0.0851 \pm \\
0.0177\end{array}$ & $\begin{array}{l}0.0859 \pm \\
0.0107\end{array}$ \\
\hline \multicolumn{6}{|c|}{$\begin{array}{l}\text { Values are mean } \pm \text { SD, } \mathrm{n}=5-13 \text { hearts for each groups. BW: Body weight; } \mathrm{CW} \text { : Carcass weight; TL: } \\
\text { Total length; BL: Body length; HM: Heart mass; VM: Ventricular mass; RHM: Relative heart mass = } \\
{[(\mathrm{HM} / \mathrm{BW}) \times 100] ; \text { RVM: Relative ventricular mass }=[(\mathrm{VM} / \mathrm{BW}) \times 100] . \mathrm{a}, \mathrm{b} \text { and } \mathrm{c} \text { represent }} \\
\text { significantly different groups }(P<0.05) \text {. }\end{array}$} \\
\hline
\end{tabular}

\section{Fibrillar collagen level increased and cardiomyocyte necrosis caused structural damage to the heart}

To observe the histopathological changes of $A$. baerii heart failure, heart sections were stained following the protocols of $\mathrm{H} \& \mathrm{E}$ and Masson trichrome staining. Masson's trichrome staining showed that the changes were extremely pronounced in the compact layer in the heat-stressed group (Fig. 3A). The most obvious changes were the decrease in the thickness of the compact layer and the dramatic increase in the content of fibrillar collagen (Fig. 3A, B and E). Meanwhile, CHS also caused the density of the spongy layer to significantly decrease and the fibrillar collagen content to significantly increase (Fig. 3C, D). All indices showed different degrees of recovery after the recovery period (Fig. 3). 
Sections were systematically examined, revealing that the most obvious lesions were mainly concentrated in the ventricular tissue. Specifically, $\mathrm{H}$ \& E staining showed massive necrosis of cardiomyocytes in the compact layer of the ventricle in group $\mathrm{H}$, exhibiting symptoms of myocardial atrophy and inflammatory cell infiltration (Fig. 4A c, f, g). The histopathological score of the compact layer also significantly increased $(P<0.05)$ (Fig. 4A h). CHS also resulted in significant increases in epicardial fat and increased blurring of the boundary between the compact layer and the epicardium compared to the control (Fig. 4A g). To further confirm the presence of necrosis in the cardiomyocytes we tested the myocardial enzyme leakage levels in the plasma. In general, the levels of myocardial enzymes exhibited an upward trend under CHS, but the increase in CK was most obvious (Fig. 4D) $(P<0.05)$.

\section{The regulatory mechanism of cardiac fibrosis and myocardial necrosis under CHS}

To study the specific role of cardiac fibrosis and myocardial necrosis in the heart of $A$. baerii, we selected the group $\mathrm{C}, \mathrm{H}$ and $\mathrm{R}-\mathrm{H}$ heart for transcriptome sequencing. Transcriptomics analysis showed that fibrous collagen deposition increased after CHS. It is manifested as an increase in the production of collagen fibers (COL1A, COL2A, COL4A and COL6A) and a down-regulation of the expression of genes that regulate the degradation of collagen fibers (COLase 3 and COLase 4). In the necroptosis regulatory network, down-regulated of the Caspase 8, leading to inhibition of apoptotic pathways in cardiomyocytes and shifting to necrosis. The present studies have shown that mitochondrial fission may be an important inducement of cardiomyocyte necrosis, accompanied by the significant up-regulation of DNM1L and Hsp 90 after CHS (Fig. $6 \mathrm{~L}$ and M). However, timely cooling can alleviate the process of cardiac fibrosis and cardiomyocyte necrosis to a certain extent.

\section{Blocked heart activity under severe CHS}

To further investigate the association between changes in cardiac tissue structure and cardiac function, echocardiography combined with B-mode imaging and Doppler imaging were used. In the current study, both the ventricular end-diastolic area (VEDA) and ventricular end-systolic area (VESA) showed increasing trends in CHS conditions, with significant differences in the VESA $(P<0.05)$. After the recovery period, the $\mathrm{M}$ group remained unchanged, while the VEDA and VESA continued to rise in the $\mathrm{H}$ group $(P<0.05)$ (Fig. 7A and B). CHS resulted in a significant reduction in atrioventricular valve diameter, which did not return to normal levels after the recovery period (Fig. 7C). Meanwhile, a marked HR increase was observed in the $\mathrm{H}$ group compared to control group, but after recovery the HR was no longer elevated (Fig. 7D).

\section{CHS caused decrease in heart ejection effectiveness}

Impaired cardiac activity may directly change blood flow parameters. Therefore, ultrasound Doppler analysis was used to analyze the changes in cardiac blood flow velocity. After $\mathrm{CHS}$, there was no significant change in AA blood flow velocity in group $\mathrm{M}$, but group $\mathrm{H}$ showed a significant increase (Fig. 8). The blood flow velocities from the BA and AV were significantly reduced in the recovered fish 
from group $\mathrm{H}$ compared to the control fish (Fig. 8B, $\mathrm{C})(P<0.05)$. Except group $\mathrm{M}$ and $\mathrm{H}$, no significant differences in AA blood flow velocity were detected among groups.

In addition, indicators of cardiac function were measured using the Cardiac Function Measurement Package. With increasing CHS intensity, SV, CO, and VET showed significant and sequential decreases in the $\mathrm{M}$ and $\mathrm{H}$ groups compared to the control group $(P<0.05)$ (Fig. 7F, $\mathrm{G}$ and $\mathrm{H})$. However, the opposite trend was true for the PI of group H (Fig. 7E). Considering the trends in HR, which suggested decreased myocardial contractility and increased cardiac afterload, the changes could be characterized as those of a typical high-resistance and low-output heart failure. During the recovery period, almost all indicators tended to return to normal levels (group C), in particular, SV, CO, and VET were significantly increased in the R-H group $(P<0.05)$ (Fig. 7F, G and $\mathrm{H})$. However, the SV and $\mathrm{CO}$ levels did not return to normal levels in group $\mathrm{H}$.

\section{Discussion}

CHS caused by the increase of water temperature in aquaculture ponds in summer may lead to heart failure of sturgeon and affect the development of sturgeon industry. However, how CHS affects the changes in sturgeon's heart structure and function is still unclear and its effect on fish production significance for aquaculture need to be further studied. This study explored the changes in the structure and function of the sturgeon's heart under CHS, and tried to establish the connection. Combined with histopathology, echocardiographic detection technology and transcriptomics analysis, it was found that CHS caused $A$. baerii's ventricular fiber collagen content to increase and myocardial necrosis, which caused $A$. baerii's cardiac dysfunction and decreased pumping effectiveness. After the recovery period, although most results showed that the heart function of the heat-stressed group had a tendency to recover. However, there were still injuries in group $\mathrm{H}$ that could not eliminate the symptoms. It indicates that the sturgeon heart has a certain ability to regulate itself, which may be accomplished through the regulation of fiber collagen content and the proliferation of myocardial cells $[35,46,47]$.

The present study identified the proliferation of myocardial interstitial myocardial collagen and myocardial necrosis as important factors leading to the cardiac imbalance and heart failure. Myocardial fibrosis is an important causes of cardiac dysfunction in A. baerii. Myocardial fibrosis is a pathological reaction that causes an imbalance in the collagen ratio due to increased deposition of collagen in the myocardial interstitium, which may induce a variety of cardiovascular diseases $[26,48]$. Studies have shown that increased ventricular stiffness and decreased cardiac function have been observed in Atlantic cod (Gadus morhua) at warm acclimation [31]. Meanwhile, in zebrafish, where there is significantly less thick collagen fibres in the hearts of fish acclimated to $20^{\circ} \mathrm{C}$ compared with those acclimated to $28^{\circ} \mathrm{C}$ [46]. We guess that the zebrafish myocardial collagen fibers will show the opposite trend after warm acclimation. Fibrous collagen deposition increases ventricular stiffness. Similarly, after CHS, the proportion of $A$. baerii's ventricular fiber collagen increased significantly in group $\mathrm{H}$. Fibrous collagen increases the passive stiffness of the chamber wall, and excessive myocardial fibrosis will reduce chamber compliance and dilatability, which may have a significant impact on ventricular diastolic filling 
[28]. We believe that it is caused by delayed or hindered degradation of collagen fibers and over-synthesis to maintain part of the heart function. Therefore, we observed that the VEDA of the ventricle remains unchanged but the VESA increases significantly. Meanwhile, CO and SV in the CHS group were significantly reduced and implying decreased pumping effectiveness. Such changes are common, and permanent, in the hearts of patients suffering from cardiac hypertension, dilated cardiomyopathy or chronic congestive heart failure, and collagen fiber increased greatly contribute to the associated diastolic dysfunction and eventual heart failure [49-52]. Considering the importance of the ventricles to the whole heart, this may be an important factor in inducing heart failure in sturgeon. Study found that the coldinduced increase in salmon heart collagen deposition was reversed after experiencing chronic warming $[23,35]$. Therefore, the significant decrease in collagen content of $A$. baeriis ventricular fibers during the recovery period can be attributed to the degradation of collagen.

Furthermore, cardiac myocytes necrosis, which is one of the main pathological changes in the hearts of A. baerii under CHS, can cause cardiac atrophy and dysfunction $[32,53]$. Study found that the $\mathrm{H}_{2} \mathrm{O}_{2}$ consumption capacity of cardiac mitochondria in rainbow trout decreased with increasing temperature, which may increase the risk of oxidative stress and cause cardiomyocyte necrosis [54]. In present study, histopathology and myocardial enzyme levels confirmed the presence of necrosis of myocardial cells. And transcriptomics studies have found that cardiac mitochondrial damage may mediate myocardial cell necrosis. Experiment found that the delayed delivery of ion channel flux action potentials caused by the collapse of cardiac myocytes may seriously affect pumping in fish hearts. [55]. However, as an increase in physiological temperature increases HR in fish $[16,56]$, this suggests that the heart is pumping less blood per beat at a faster rate. Therefore, we have observed an increasing trend of the AA flow velocity under chronic heat stress (group H) in sturgeon, but the BV and AV flow do not change significantly. It explains the significant increase in $A$. baerii heart rate and the significant decrease in SV after CHS (group $H)$. Meanwhile, damage to myocardial structure will cause insufficient energy supply, abnormal ventricular contraction (increased ventricular volume at the end-systolic area), and lead to a decrease in stroke volume and pumping efficiency [57]. Therefore, cardiac function in A. baerii under heat stress is imply a reduction in myocardial contractility and an augmentation of cardiac afterload, matching the typical characteristics of high-resistance and low-output heart failure.

Like most cold-water fish fish, the sturgeon's living space and life activities are under threat and being compressed by rising water temperatures, which is apparent in the Yangtze River Basin $[4,6]$. In addition, sturgeon grow slowly and usually take 7-8 years to reach sexual maturity [20]. Cardiac dysfunction is undoubtedly an important risk factor that could hinder the growth and development of sturgeon, potentially increasing their age at maturation. Due to the inability of their hearts to quickly respond to high water temperatures, most sturgeon could exhibit "cardiac syndrome" (like $S$. salar) in the high water temperature environment in summer $[58,59]$. According to the results of the echocardiography and microstructure observations after the recovery period, it was found that the sturgeon's heart was unable to completely return to normal working levels. Current evidence suggests that the upper limits of temperature tolerance in fish are primarily determined by the points at which their hearts fail to maintain 
tissue perfusion and adequate oxygenation [60, 61]. Disorders of heart function may affect fish swimming performance, predator avoidance, foraging behavior, and alter a species geographic distribution [62, 63], leading to the local extinction of fish species [4]. Therefore, avoiding high water temperature sturgeon farming and seeking effective cooling methods may be important directions for sturgeon farming in the future. In addition, behavioral observations of juvenile sturgeon should be performed regularly during the conservation and breeding of endangered sturgeon species, and antistress prevention products should be added appropriately to improve heart health.

\section{Conclusions}

In conclusion, we have confirmed that timely cooling of the culture water can alleviate the heart failure of A. baerii caused by CHS. CHS can cause $A$. baerii to show obvious "heart failure" characteristics, and cardiac function examination reveal a reduction in myocardial contractility and an augmentation of cardiac afterload, matching the typical characteristics of high-resistance and low-output heart failure characteristics. The rate of $A$. baerii's cardiac fibrosis and myocardial necrosis was relieved after the culture water was cooled. Therefore, the present study shows that maintaining normal growth water temperature and timely cooling during cold-water fish farming are important measures for healthy farming.

\section{Declarations}

\section{Ethics approval statement}

All animal handling procedures were approved by the animal care and use committee of Sichuan Agricultural University in accordance with the animal experiment guidelines under license NO. ZCY2019202031.

\section{Acknowledgements}

The authors would like to express their thanks to the personnel of these teams for their selfless assistance.

\section{Authors' contributions}

All authors read and approved the final manuscript. Chaoyang Zhang, Miao Zhang and Zihan Xu contributed the work equally. All authors read and approved the final manuscript. Chaoyang Zhang: Writing original draft, Methodology, Investigation. Miao Zhang: Investigation. Zihan Xu: Data curation, Software. Datian Li: Data curation. Quan Gong: Methodology, Software. Xiaoli Huang: Formal analysis, Resources, Validation. Jiayun Wu: Formal analysis. Zhi He and Xiaogang Du: Data curation, Supervision, Investigation. Defang Chen and Jun Jiang: Supervision, Investigation. Jun Du: Resources and Formal analysis. Shiyong Yang: Project administration, Writing original draft, Investigation, Methodology, Conceptualization, Contribution. 


\section{Declaration of Competing Interest}

Authors declare that the research was conducted without any commercial or financial relationships that could be construed as a potential conflict of interest.

\section{Funding}

This work was supported by the Project of Provincial 14th Five Years' Animal Breeding of Sichuan Province (2021YFYZ0015); the Science and Technology Achievement Transfer and Transformation Demonstration Project of Sichuan Province (2021ZHCG0065); the Applied Basic Research from Technological Office of Sichuan Province (2019YJ0515); and the Two Sides Supporting Plan in Sichuan Agricultural University (00770103).

\section{Availability of data and materials}

All data generated or analyzed were included in the article. All materials are available from the corresponding author, on reasonable request.

\section{Ethics approval and consent to participate}

All animal handling procedures were approved by the animal care and use committee of Sichuan Agricultural University in accordance with the animal experiment guidelines under license NO. ZCY2019202031.

\section{Consent for publication}

Not applicable.

\section{Competing interests}

The authors declare no conflict of interest.

\section{Author details}

${ }^{1}$ Department of Aquaculture, Sichuan Agricultural University, Chengdu, Sichuan 611130, China

${ }^{2}$ Fisheries Research Institute, Sichuan Academy of Agricultural Sciences, Chengdu 611731, China

${ }^{3}$ College of Life Sciences, Sichuan Agricultural University, Ya'an, Sichuan 625000, China

\section{References}

1. Anderson M: Climate Change 2014: Synthesis Report. Library Journal 2016, 141(9):28-28.

2. Seneviratne SI, Donat MG, Mueller B, Alexander LV: No pause in the increase of hot temperature extremes (vol 4, pg 161, 2014). Nature Climate Change 2014, 4(5):320-320. 
3. Kaushal SS, Likens GE, Jaworski NA, Pace ML, Sides AM, Seekell D, Belt KT, Secor DH, Wingate RL: Rising stream and river temperatures in the United States. Frontiers in Ecology \& the Environment 2010, 8(9).

4. Zhang H, Kang M, Wu J, Wang C, Li J, Du H, Yang H, Wei Q: Increasing River Temperature Shifts Impact the Yangtze Ecosystem: Evidence from the Endangered Chinese Sturgeon. Animals 2019, 9(8).

5. Larnier K, Roux H, Dartus D, Croze O: Water temperature modeling in the Garonne River (France). Knowledge and Management of Aquatic Ecosystems 2010(398).

6. Huang Z, Wang L: Yangtze Dams Increasingly Threaten the Survival of the Chinese Sturgeon. Current Biology 2018, 28(22):3640-3647.

7. Marber MS, Latchman DS, Walker JM, Yellon DM: Cardiac stress protein elevation 24 hours after brief ischemia or heat stress is associated with resistance to myocardial infarction. Circulation 1993, 88(3):1264-1272.

8. Havn TB, Uglem I, Solem O, Cooke SJ, Whoriskey FG, Thorstad EB: The effect of catch-and-release angling at high water temperatures on behaviour and survival of Atlantic salmon Salmo salar during spawning migration. Journal of Fish Biology 2015, 87(2):342-359.

9. Lou B, Xu D, Xu H, Zhan W, Mao G, Shi H: Effect of high water temperature on growth, survival and antioxidant enzyme activities in the Japanese flounder Paralichthys olivaceus. African Journal of Agricultural Research 2011, 6(12):2875-2882.

10. Ahmed M: Introduction to Modern Climate Change. Science of the Total Environment 2020, 734.

11. Miller GM, Kroon FJ, Metcalfe S, Munday PL: Temperature is the evil twin: effects of increased temperature and ocean acidification on reproduction in a reef fish. Ecological Applications 2015, 25(3):603-620.

12. Breckels RD, Neff BD: The effects of elevated temperature on the sexual traits, immunology and survivorship of a tropical ectotherm. Journal of Experimental Biology 2013, 216(14):2658-2664.

13. Ficke AD, Myrick CA, Hansen LJ: Potential impacts of global climate change on freshwater fisheries. Reviews in Fish Biology and Fisheries 2007, 17(4):581-613.

14. Yang S, Yang X, Li Y, Li D, Du X: The multilevel responses of Acipenser baerii and its hybrids (A. baerii $\nabla \times$ A. schrenckii $\nabla)$ to chronic heat stress. Aquaculture 2021, 541(4):736773.

15. Iftikar FI, Morash AJ, Cook DG, Herbert NA, Hickey AJR: Temperature acclimation of mitochondria function from the hearts of a temperate wrasse (Notolabrus celidotus). Comparative Biochemistry and Physiology a-Molecular \& Integrative Physiology 2015, 184:46-55.

16. Lee L, Genge CE, Cua M, Sheng X, Rayani K, Beg MF, Sarunic MV, Tibbits GF: Functional Assessment of Cardiac Responses of Adult Zebrafish (Danio rerio) to Acute and Chronic Temperature Change Using High-Resolution Echocardiography (vol 11, e0145163, 2016). Plos One 2016, 11(2).

17. Bronzi P, Rosenthal H: Present and future sturgeon and caviar production and marketing: A global market overview. Journal of Applied Ichthyology 2014, 30(6):1536-1546. 
18. Zhang H, Wei QW, Du H, Li LX: Present status and risk for extinction of the Dabry's sturgeon (Acipenser dabryanus) in the Yangtze River watershed: a concern for intensified rehabilitation needs. Journal of Applied Ichthyology 2011, 27(2):181-185.

19. Chen X: Biology and Resource Status of Sturgeons. Beijing: Ocean Press; 2007.

20. Wei Q, Ke F, Zhang J, Ping Z, Luo J, Zhou R, Yang W: Biology, fisheries, and conservation of sturgeons and paddlefish in China. Springer Netherlands 1997.

21. Mai L, Liu X, Pan P, Sun D: Effects of water temperature on growth performance in juvenile Amur sturgeon, Sterlet and Siberian sturgeon. Chinese journal of fisheries 2014(4):15-22.

22. Petersen LH, Gamperl AK: Effect of acute and chronic hypoxia on the swimming performance, metabolic capacity and cardiac function of Atlantic cod (Gadus morhua). Journal of Experimental Biology 2010, 213(5):808-819.

23. Klaiman JM, Fenna AJ, Shiels HA, Macri J, Gillis TE: Cardiac Remodeling in Fish: Strategies to Maintain Heart Function during Temperature Change. Plos One 2011, 6(9).

24. Leal MJ, Van Eenennaam JP, Schreier AD, Todgham AE: Triploidy in white sturgeon (Acipenser transmontanus): Effects of acute stress and warm acclimation on physiological performance. Comparative Biochemistry and Physiology a-Molecular \& Integrative Physiology 2019, 229:10-17.

25. Keen AN, Klaiman JM, Shiels HA, Gillis TE: Temperature-induced cardiac remodelling in fish. Journal of Experimental Biology 2017, 220(2):147-160.

26. Pellman J, Lyon RC, Sheikh F: Extracellular matrix remodeling in atrial fibrosis: Mechanisms and implications in atrial fibrillation. Journal of Molecular and Cellular Cardiology 2010, 48(3):461-467.

27. Fomovsky GM, Holmes JW: Evolution of scar structure, mechanics, and ventricular function after myocardial infarction in the rat. American Journal of Physiology-Heart and Circulatory Physiology 2010, 298(1):H221-H228.

28. Collier P, Watson CJ, van Es MH, Phelan D, McGorrian C, Tolan M, Ledwidge MT, McDonald KM, Baugh JA: Getting to the heart of cardiac remodeling; how collagen subtypes may contribute to phenotype. Journal of Molecular and Cellular Cardiology 2012, 52(1):148-153.

29. Dimitriadi A, Geladakis G, Koumoundouros G: 3Dheart morphological changes in response to developmental temperature in zebrafish: More than ventricle roundness. Journal of Morphology 2020.

30. Anttila K, Couturier CS, Overli O, Johnsen A, Marthinsen G, Nilsson GE, Farrell AP: Atlantic salmon show capability for cardiac acclimation to warm temperatures. Nature Communications 2014, 5.

31. Syme DA, Gamperl AK, Nash GW, Rodnick KJ: Increased ventricular stiffness and decreased cardiac function in Atlantic cod (Gadus morhua) at high temperatures. American Journal of PhysiologyRegulatory Integrative and Comparative Physiology 2013, 305(8):R864-R876.

32. Kung G, Konstantinidis K, Kitsis RN: Programmed Necrosis, Not Apoptosis, in the Heart. Circulation Research 2011, 108(8):1017.

33. Anttila K: Fish heart physiology. Acta Physiologica 2019, 227:25-25. 
34. Chen Y, Li C, Wang G, Shen F, Teng T, Guo J, Weng X, Ling Q: Effect of Heat Stress on the Histopathological Features and Antioxidant Enzyme Activity in the Gills of Sander lucioperca. Journal of Hydroecology 2019, 040(004):115-120.

35. Keen AN, Fenna AJ, McConnell JC, Sherratt MJ, Gardner P, Shiels HA: The Dynamic Nature of Hypertrophic and Fibrotic Remodeling of the Fish Ventricle. Frontiers in Physiology 2016, 6.

36. Klaiman JM, Pyle WG, Gillis TE: Cold acclimation increases cardiac myofilament function and ventricular pressure generation in trout. Journal of Experimental Biology 2014, 217(23):4132-4140.

37. Morgenroth D, McArley T, Grans A, Axelsson M, Sandblom E, Ekstrom A: Coronary blood flow influences tolerance to environmental extremes in fish. Journal of Experimental Biology 2021, 224(8).

38. Chen D, Peng S, Chen D, Yang F, Liu J, Wang J, Liu Q, Huang X, Ouyang P, Wang K et al: Low lethal doses of Streptococcus iniae caused enteritis in Siberian sturgeon (Acipenser baerii). Fish \& Shellfish Immunology 2020, 104:654-662.

39. Song X, Zhao J, Bo Y, Liu Z, Wu K, Gong C: Aeromonas hydrophila induces intestinal inflammation in grass carp (Ctenopharyngodon idella): An experimental model. Aquaculture 2014, 434:171-178.

40. Domanski, Michael J: Association of Myocardial Enzyme Elevation and Survival Following Coronary Artery Bypass Graft Surgery. Jama 2012, 305(6):585-591.

41. Zhou L, Li X, Zhu Z, Shan Z, Yong JW: Signal analysis of electrocardiogram and statistical evaluation of myocardial enzyme in the diagnosis and treatment of patients with pneumonia. IEEE Access 2019, $\operatorname{PP}(99): 1-1$.

42. Fang Y, Sun Y, Luo C, Gu J, Shi Z, Lu G, Silvestre J-S, Chen Z: Evaluation of cardiac dysfunction in adult zebrafish using high frequency echocardiography. Life Sciences 2020, 253.

43. Liu T-Y, Lee P-Y, Huang C-C, Sun L, Shung KK: A Study of the Adult Zebrafish Ventricular Function by Retrospective Doppler-Gated Ultrahigh-Frame-Rate Echocardiography. leee Transactions on Ultrasonics Ferroelectrics and Frequency Control 2013, 60(9):1827-1837.

44. Sun $L$, Lien $C-L, X u X$, Shung KK: In vivo cardiac imaging of adult zebrafish using high frequency ultrasound (45-75 mhz). Ultrasound in Medicine and Biology 2008, 34(1):31-39.

45. Huang X, Feng $Y$, Tang $H$, Xiong G, Li L, Yang Y, Wang K, Ouyang P, Geng Y, Chen D et al: Candidate Animal Disease Model of Elizabethkingia Spp. Infection in Humans, Based on the Systematic Pathology and Oxidative Damage Caused by E. miricola in Pelophylax nigromaculatus. Oxidative Medicine and Cellular Longevity 2019, 2019.

46. Johnson AC, Turko AJ, Klaiman JM, Johnston EF, Gillis TE: Cold acclimation alters the connective tissue content of the zebrafish (Danio rerio) heart. Journal of Experimental Biology 2014, 217(11):1868-1875.

47. Zuppo DA, Tsang M: Zebrafish heart regeneration: Factors that stimulate cardiomyocyte proliferation. Seminars in Cell \& Developmental Biology 2020, 100:3-10.

48. Nattel S, Burstein B, Dobrev D: Atrial Remodeling and Atrial Fibrillation Mechanisms and Implications. Circulation-Arrhythmia and Electrophysiology 2008, 1(1):62-73. 
49. Jalil JE, Doering CW, Janicki JS, Pick R, Clark WA, Abrahams C, Weber KT: Structural vs. contractile protein remodeling and myocardial stiffness in hypertrophied rat left ventricle. Journal of molecular and cellular cardiology 1988, 20(12):1179-1187.

50. Jalil JE, Doering CW, Janicki JS, Pick R, Shroff SG, Weber KT: Fibrillar collagen and myocardial stiffness in the intact hypertrophied rat left ventricle. Circulation research 1989, 64(6):1041-1050.

51. Marijianowski MM, Teeling P, Mann J, Becker AE: Dilated cardiomyopathy is associated with an increase in the type I/type III collagen ratio: a quantitative assessment. Journal of the American College of Cardiology 1995, 25(6):1263-1272.

52. Gonzalez A, Lopez B, Ravassa S, San Jose G, Diez J: The complex dynamics of myocardial interstitial fibrosis in heart failure. Focus on collagen cross-linking. Biochimica Et Biophysica ActaMolecular Cell Research 2019, 1866(9):1421-1432.

53. Jayasundara N, Gardner LD, Block BA: Effects of temperature acclimation on Pacific bluefin tuna (Thunnus orientalis) cardiac transcriptome. American Journal of Physiology-Regulatory Integrative and Comparative Physiology 2013, 305(9):R1010-R1020.

54. Isei MO, Stevens D, Kamunde C: Temperature rise and copper exposure reduce heart mitochondrial reactive oxygen species scavenging capacity. Comparative Biochemistry and Physiology CToxicology \& Pharmacology 2021, 243.

55. Vornanen M: The temperature dependence of electrical excitability in fish hearts. Journal of Experimental Biology 2016, 219(13):1941-1952.

56. Badr A, El-Sayed MF, Vornanen M: Effects of seasonal acclimatization on temperature dependence of cardiac excitability in the roach, Rutilus rutilus. Journal of Experimental Biology 2016, 219(10):1495-1504.

57. Jain CC, Borlaug BA: Hemodynamic assessment in heart failure. Catheterization and Cardiovascular Interventions 2020, 95(3):420-428.

58. Mercier C, Aubin J, Lefranois C, Claireaux G: Cardiac disorders in farmed adult brown trout, Salmo trutta L. Journal of Fish Diseases 2000, 23(4):243-249.

59. Poppe TT, Taksdal T, Bergtun PH: Suspected myocardial necrosis in farmed Atlantic salmon, Salmo salar L.: a field case. Journal of Fish Diseases 2007, 30(10):615-620.

60. Seebacher F, White CR, Franklin CE: Physiological plasticity increases resilience of ectothermic animals to climate change. Nature Climate Change 2015, 5(1):61-66.

61. Farrell AP: Environment, antecedents and climate change: lessons from the study of temperature physiology and river migration of salmonids. Journal of Experimental Biology 2009, 212(23):37713780.

62. Paragamian VL, Beamesderfer R, Ireland SC: Status, Population Dynamics, and Future Prospects of the Endangered Kootenai River White Sturgeon Population with and without Hatchery Intervention. Transactions of the American Fisheries Society 2005, 134(2).

63. Hofmann GE, Todgham AE: Living in the Now: Physiological Mechanisms to Tolerate a Rapidly Changing Environment. Annual Review of Physiology 2010, 72:127-145. 


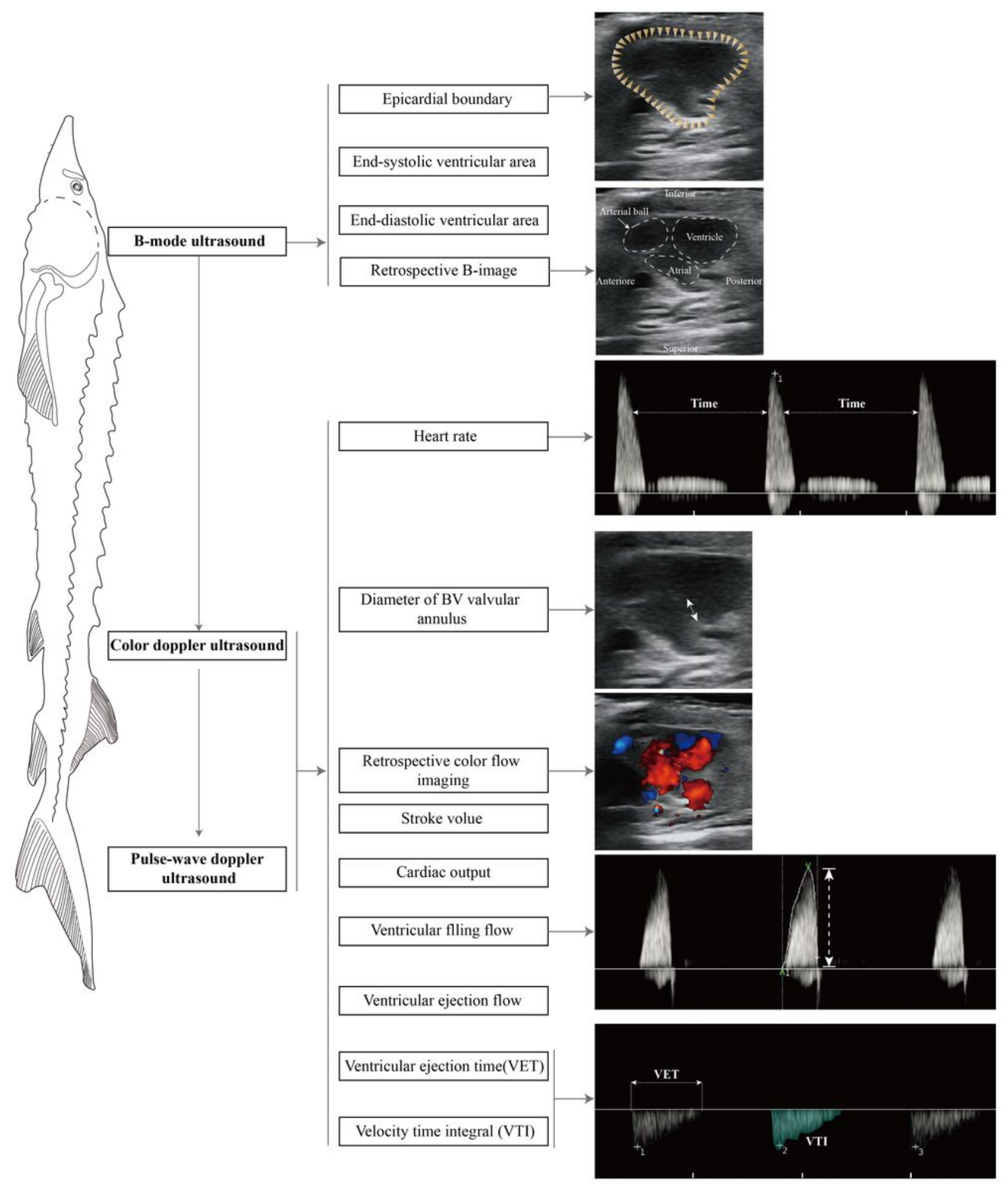

\section{Figure 1}

The echocardiography detection procedures for analysis of various cardiac parameters in A. baerii. Typical echocardiographic images of the sturgeon, showing the epicardial boundary, ventricular filling 
flow (AV flow), and ventricular ejection flow (BV flow). Relevant parameter values were automatically generated by the Cardiac Function Measurement Package.

A

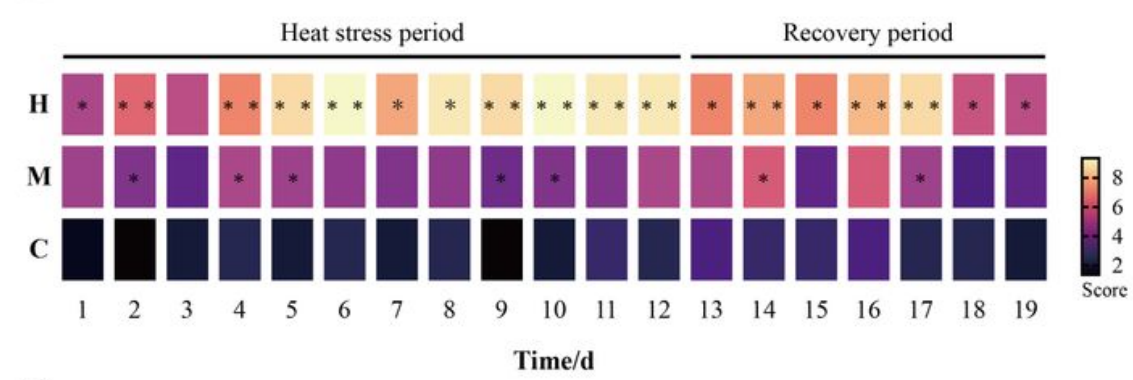

C

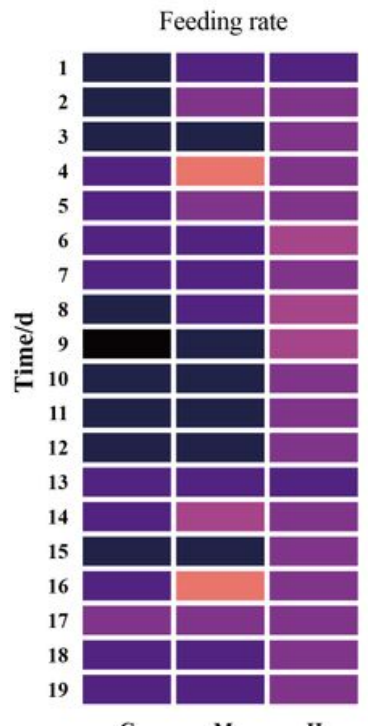

Swimming speed

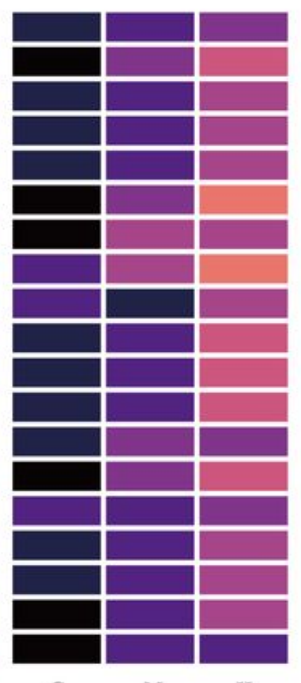

Imbalance rate

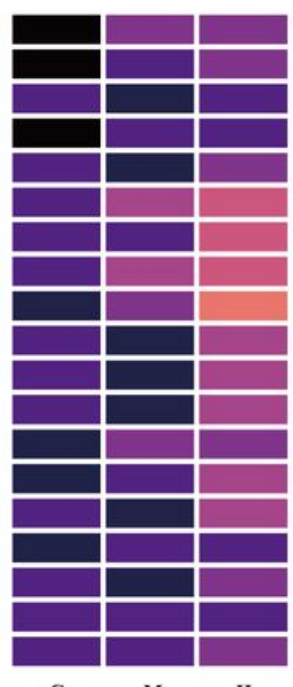

Respiratory rate
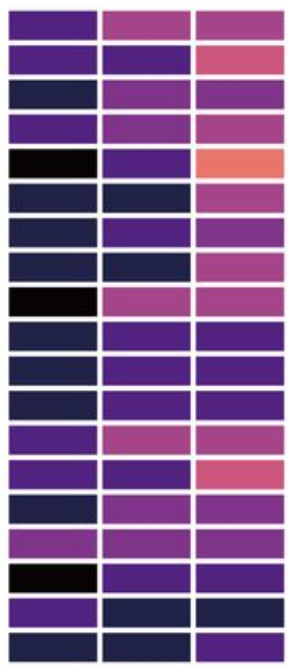

$\begin{array}{lll}\text { C } & \text { M } & \text { H }\end{array}$
B

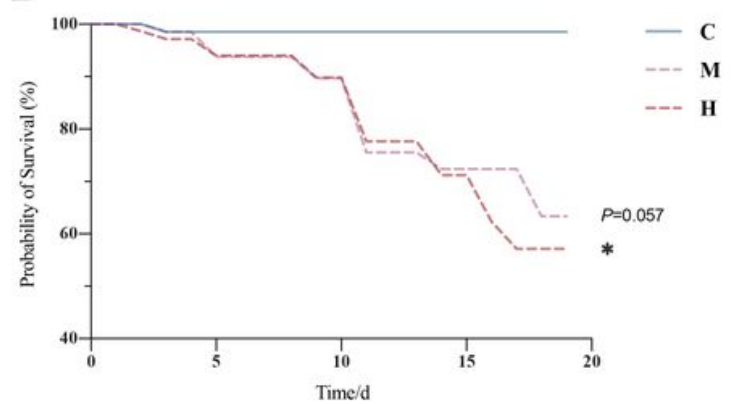

Cardiac color Percentage of ventricular injury

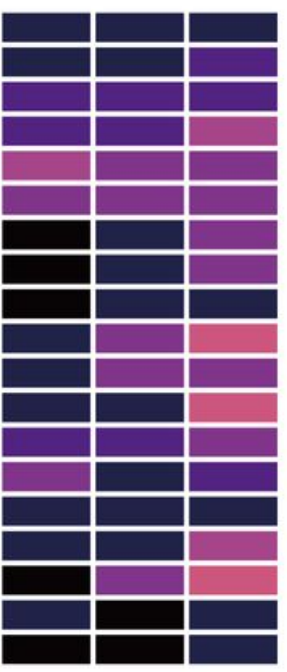

$\begin{array}{lll}\text { C } & \text { M } & \text { H }\end{array}$

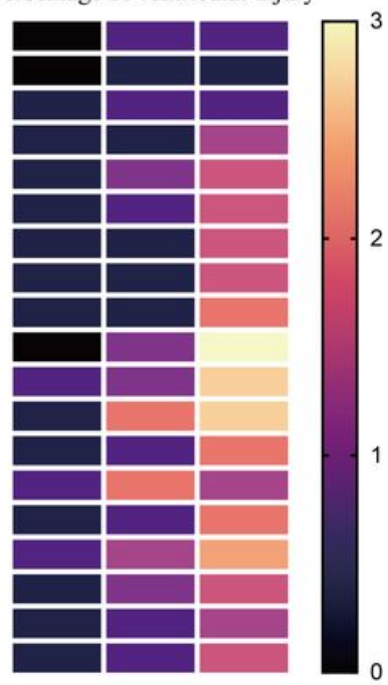

C $\quad$ M $\quad$ H

Figure 2

The HDAl (A) and survival rate \% (B) of A. baerii in different temperature groups at different time points. HDAl component parts, including: feeding rate; swimming speed; imbalance rate; respiratory rate; cardiac color; and percentage of ventricular injury (C). Survival curves were estimated by the Kaplan-Meier method, and significance analysis was performed by the log-rank test. $\mathrm{P}<0.05$ ( $\left.^{*}\right)$ and $P<0.01$ (**) indicate that groups are significant or extremely significant different from the control group. 
A
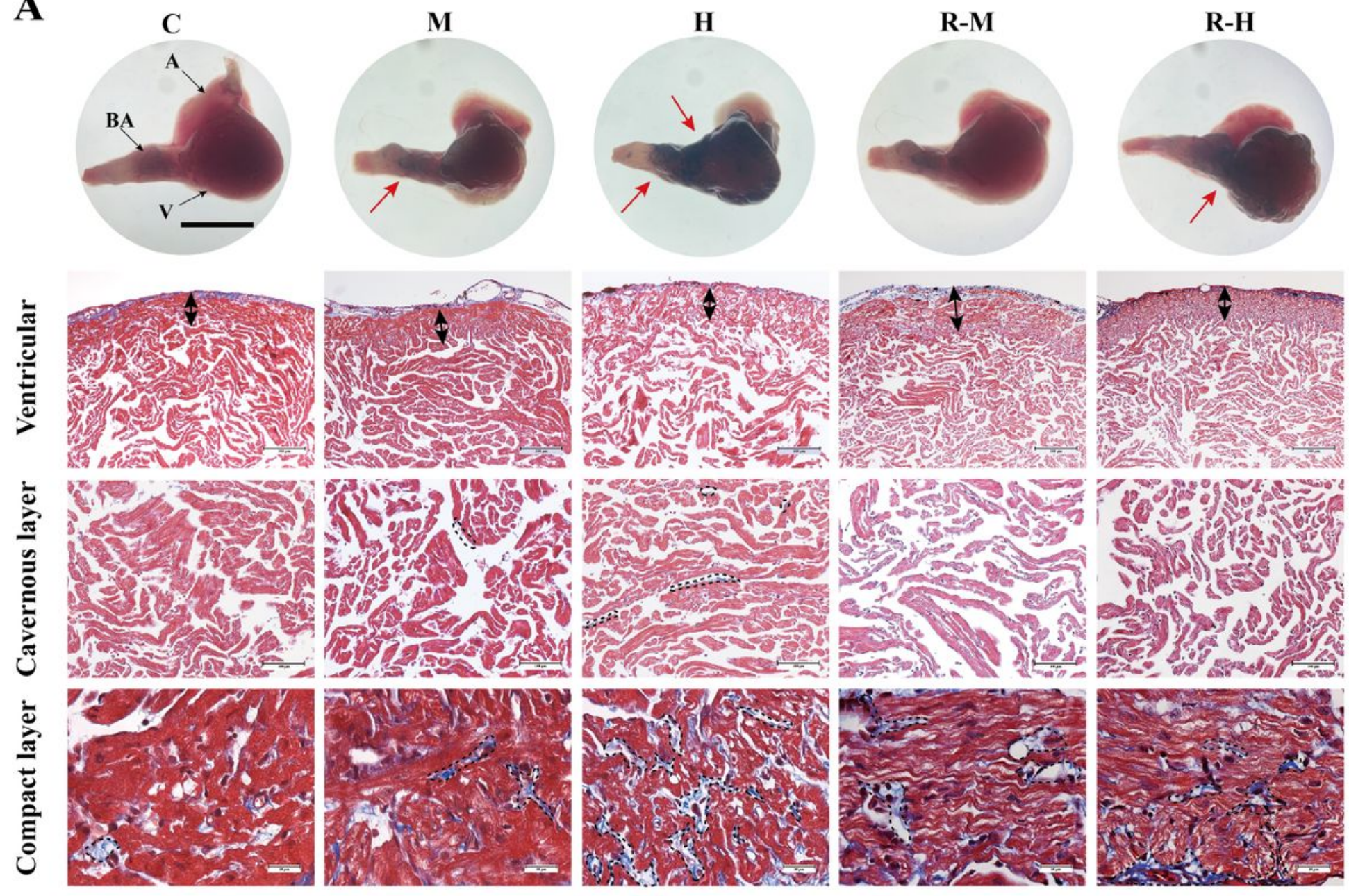

B
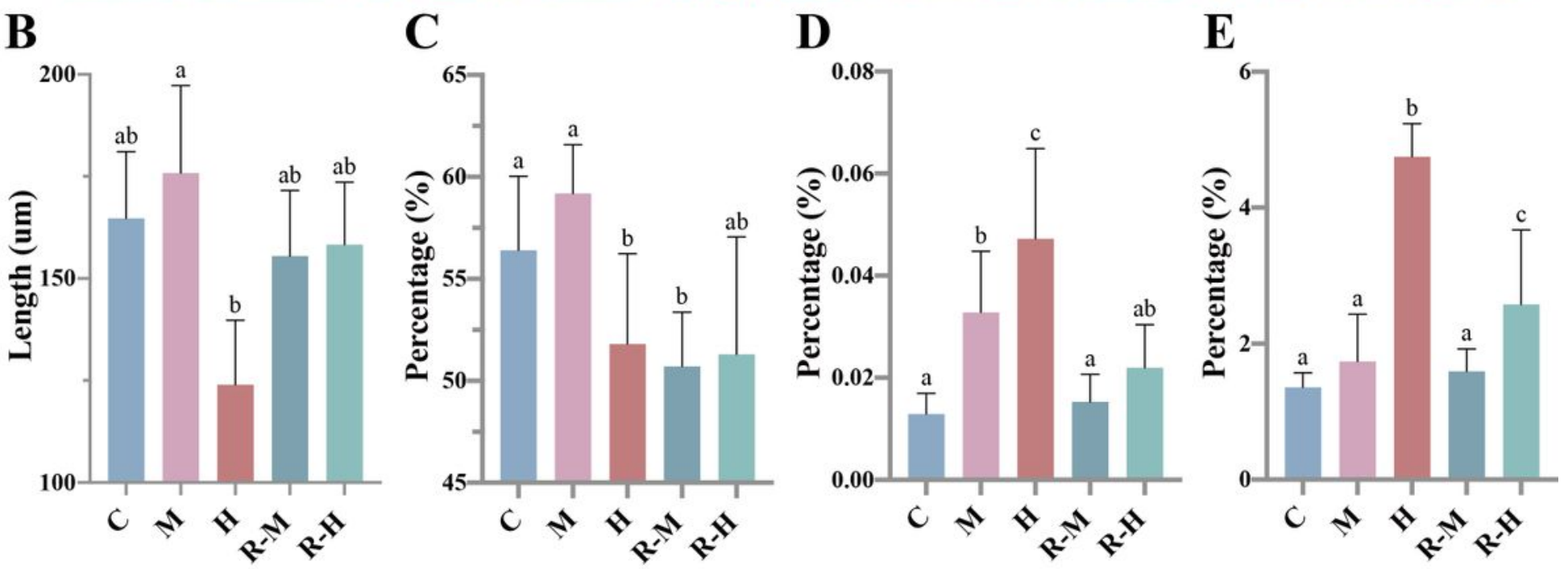

Figure 3

Morphologies, thicknesses and fibrillar collagen content of A. baerii hearts or ventricles in the control, after $\mathrm{CHS}$ and the recovery period. A: The dynamic process of cardiac morphology and the histopathology of the ventricle (Arrowheads indicate ventricular compact layer thickness, dashed lines highlight myocardial collagen and red arrows indicate black areas in the ventricles and arterial bulbs. V: Ventricle; A: Atrium; BA: Bulbus arteriosus.) B: Thickness of the compact layer; C: Density of the sponge 
layer; D and E: Content of fibrillar collagen in the myocardium of the sponge and the cavernous layer, respectively. Different lowercase letters indicate significant differences between groups $(P<0.05)$.

A
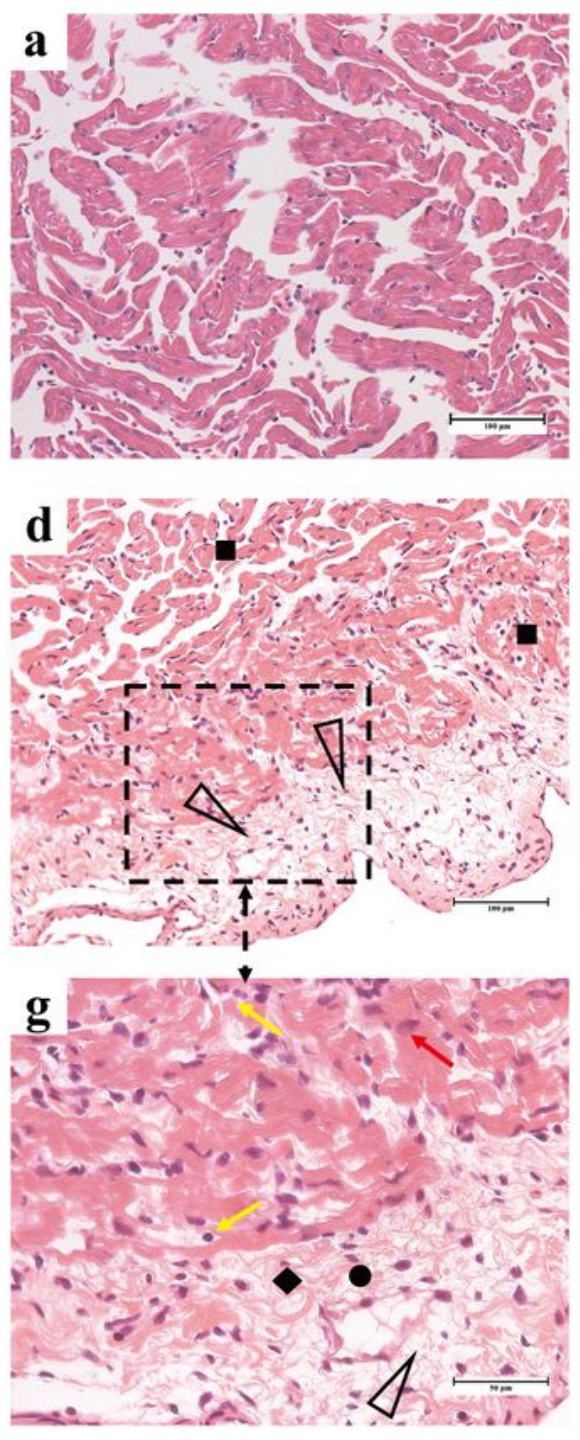

B

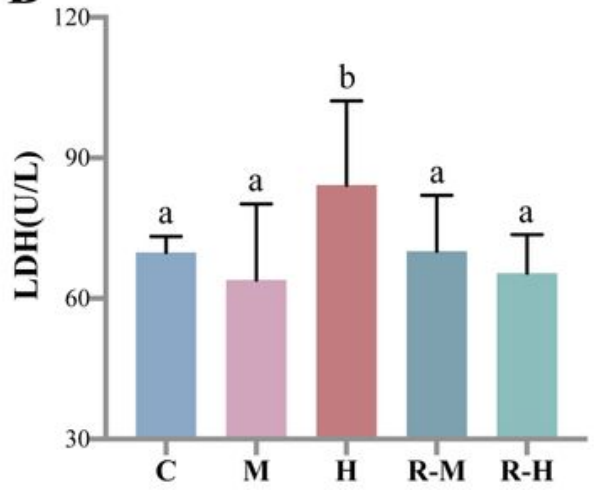

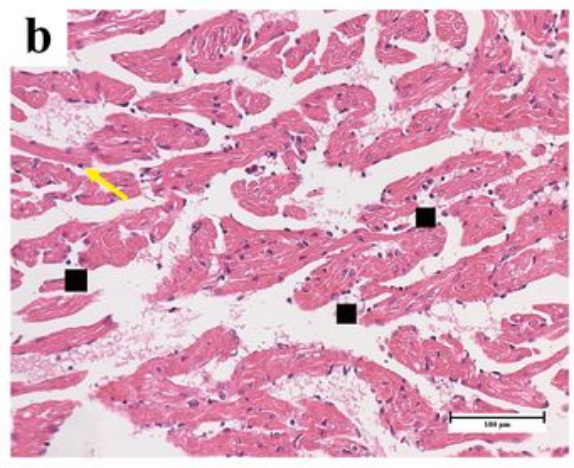

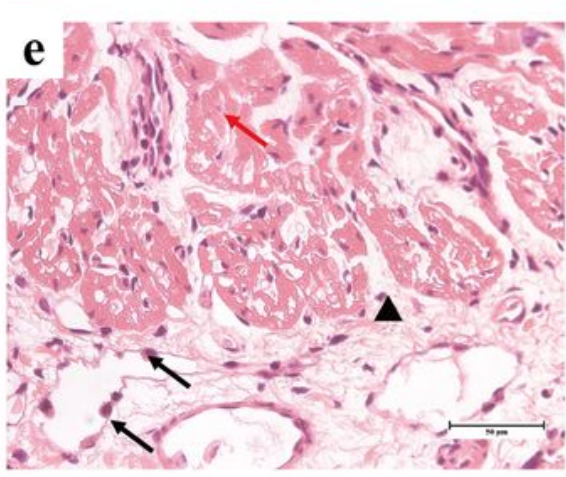

\section{h}

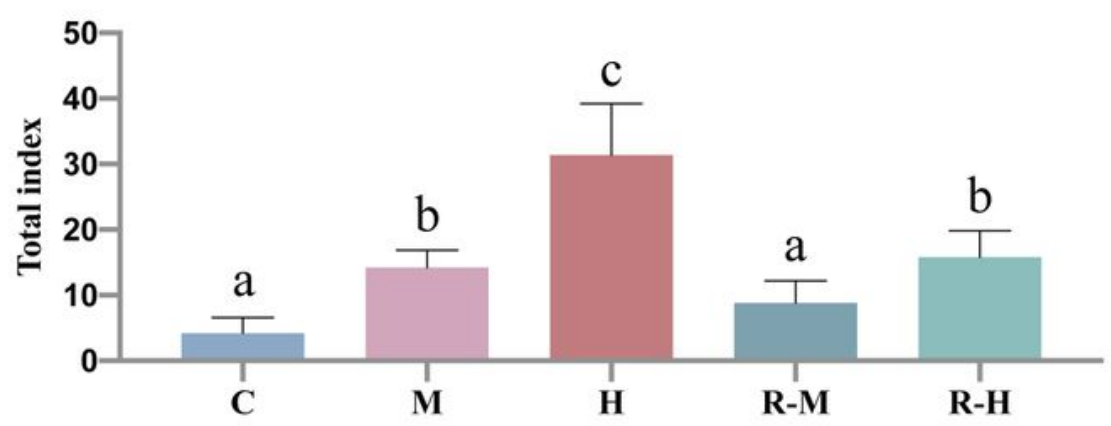

C

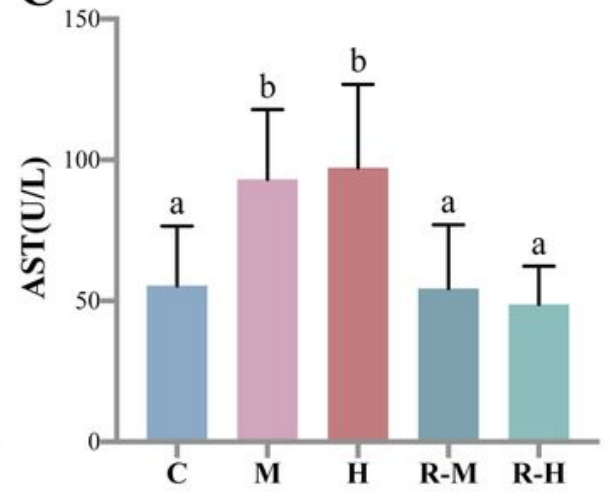

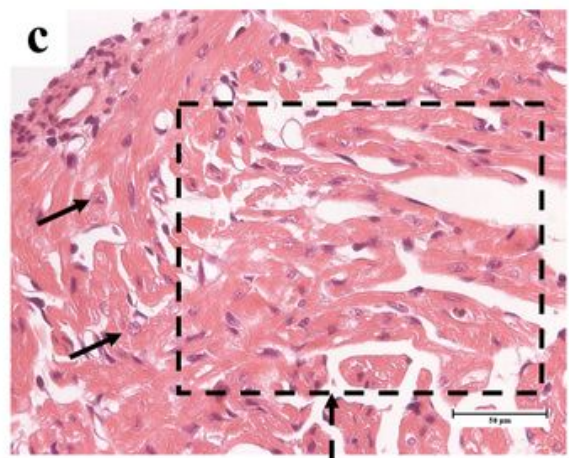

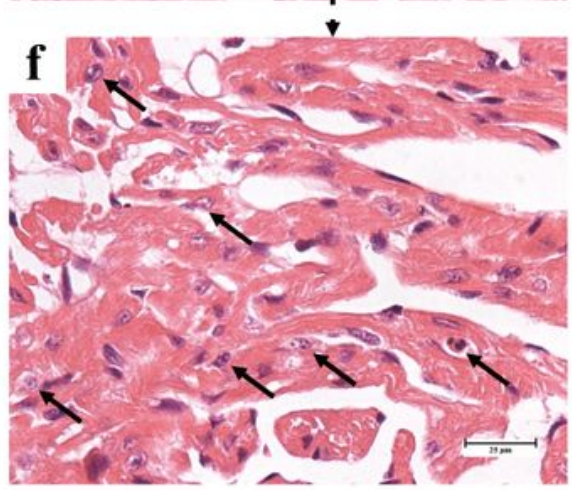

D

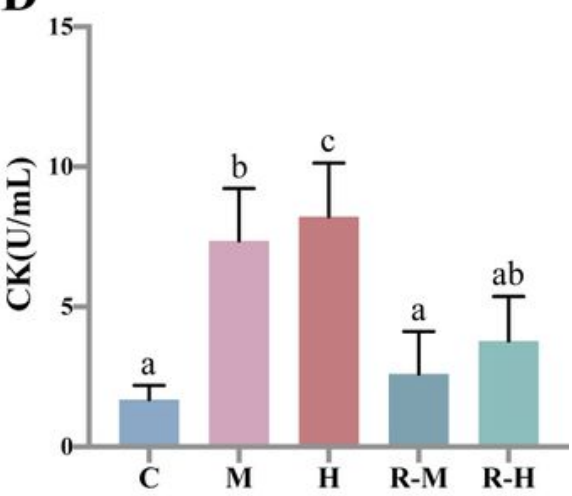

Figure 4

Histopathological examination of the ventricles and myocardial enzymes detection in the plasma of $A$. baerii under CHS. A: Histopathological examination of the ventricles of A. baerii. a: Healthy heart of A. baerii; b: Massive infiltration by inflammatory cells in the spongy layer (Group M); c and f: Ventricular 
spongy myocardial necrosis (Group H); d and g: Infiltration of inflammatory cells in the ventricle, blurring and collagenization of the epicardial border (Group H); e: Ventricular microvascular injury in Group H ( $\rightarrow$ : necrotic cells; $\rightarrow$ : nucleolysis; $\rightarrow$ : karyopyknosis; $\mathbf{\square}$ : inflammatory cell infiltration; $\bullet$ : myofibrillar atrophy of the dense layer of the ventricle; $\downarrow$ : myocardial atrophy in the dense layer; $\mathbf{\Delta}$ :blurred epicardial border; triangular arrowhead: pericardial myocardial collagen); h: Overall health status (total index) of ventricles in different groups based on histopathological lesions. A: LDH; B: AST; C: CK. Different lowercase letters indicate significant differences between groups $(P<0.05)$.

\section{Figure 5}

DEGs of fibrous collagen regulation-axis in A. baerii. Mapping the fibrous collagen regulation-axis network in the heart of $A$. baerii based on transcriptome data. A-l: the column map showed the expression level of reads of regulate collagen deposition genes in the transcriptome $(n=3$, data were presented as

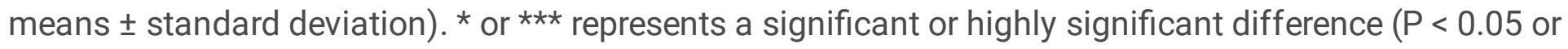
$P<0.001)$ between two groups. 

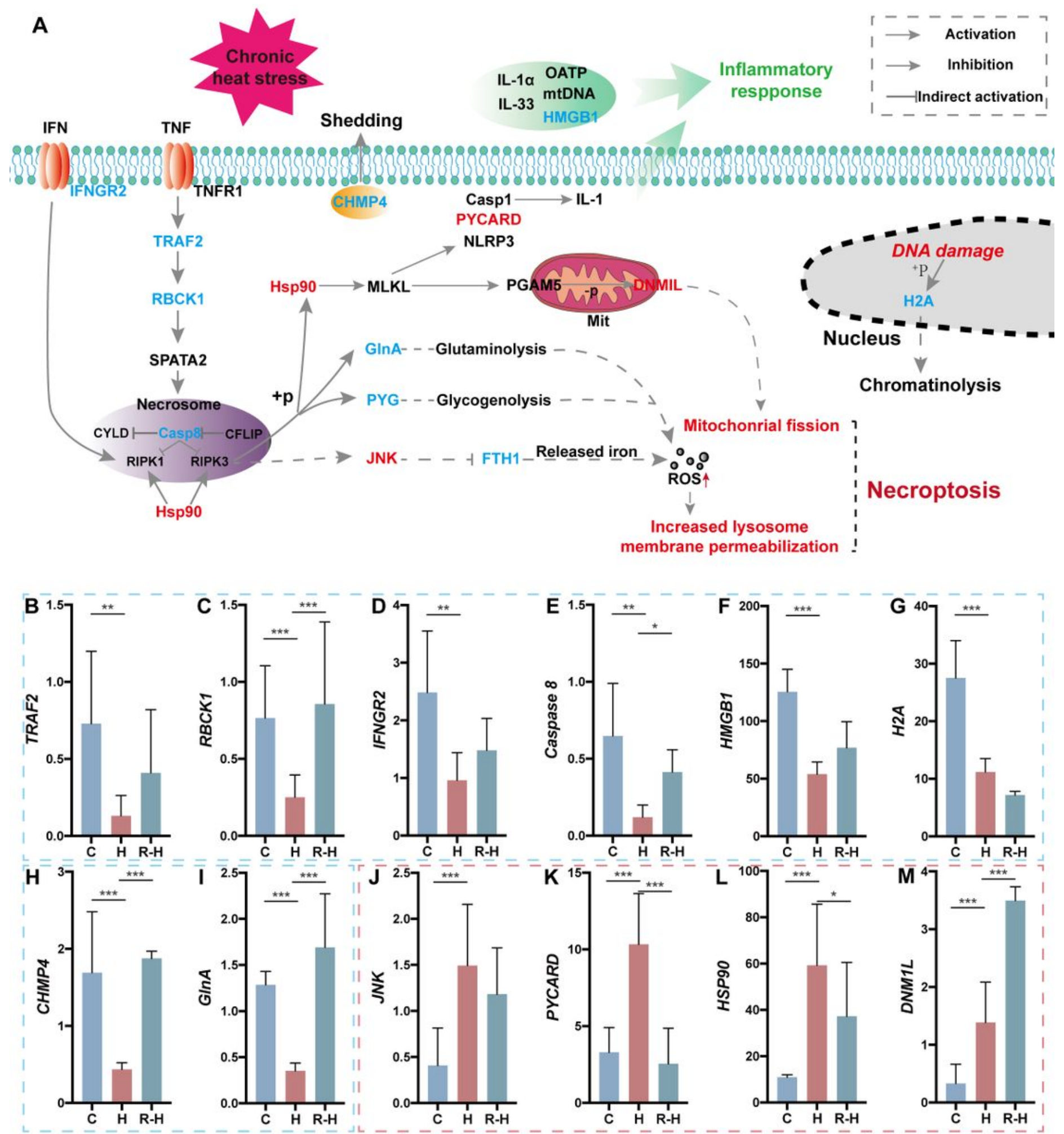

\section{Figure 6}

DEGs of necroptosis regulatory pathway in A. baerii. A: Mapping the necroptosis regulatory network in the heart of A. baerii based on transcriptome data. The red and green character indicate the up regulation and down regulation of DEGs, respectively. B-K: the column map showed the expression level of reads of regulate necroptosis regulatory pathway genes in the transcriptome $(n=3$, data were presented as means 
\pm standard deviation). ${ }^{*}, *$ or $* \star \star$ represents a significant, extremely or highly significant difference $(\mathrm{P}<$ $0.05, \mathrm{P}<0.01$ or $\mathrm{P}<0$. 001) between two groups.
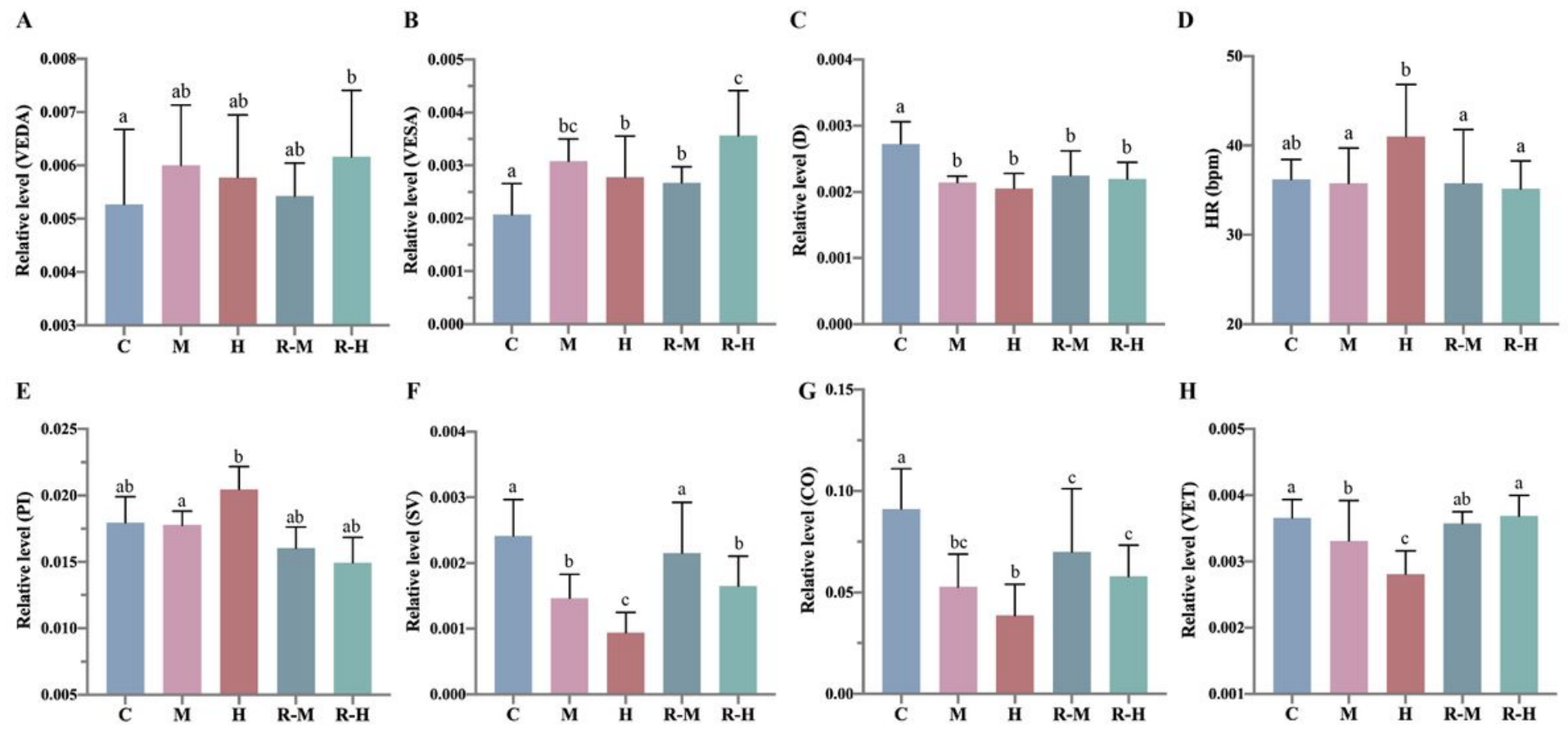

\section{Figure 7}

Ventricular activity, outflow and inflow parameters in A. baerii measured by B-mode and Doppler echocardiography. A and B: Ventricular end-diastolic area (VEDA) and ventricular end-systolic area (VESA), respectively, evaluated by area (mm2); C: Atrioventricular annulus diameter; D: Heart rate. E: Pl; F: SV; G: CO; H: VET. All echocardiographic results were standardized by body weight. Different lowercase letters indicate significant differences between groups $(P<0.05)$. 


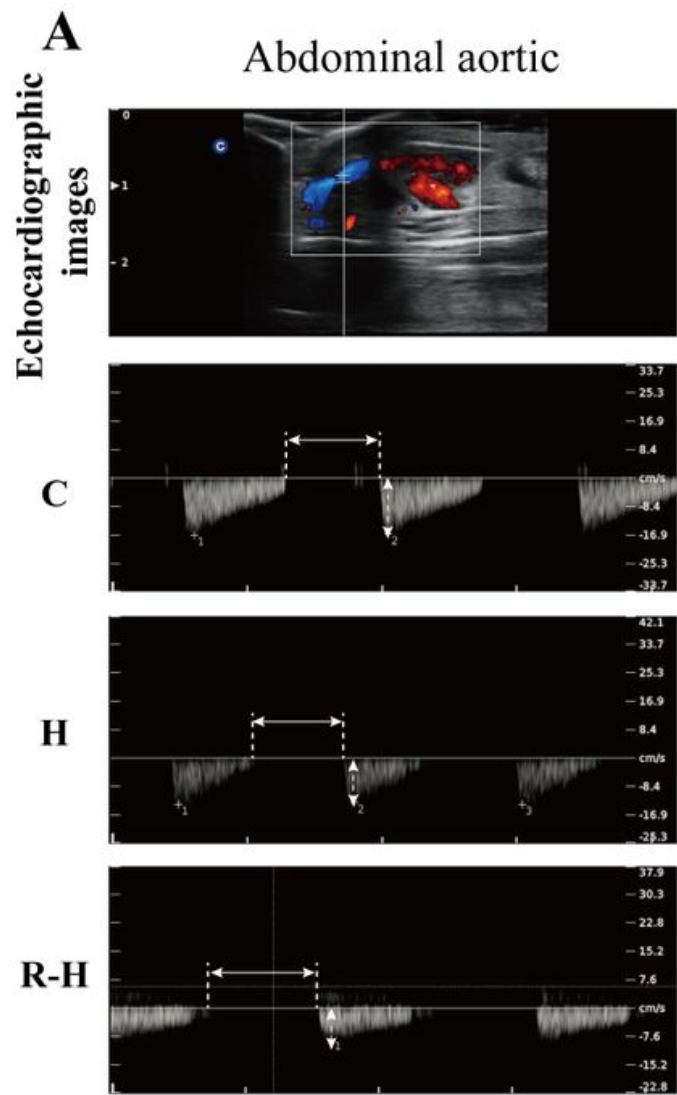

Bulboventricular valve
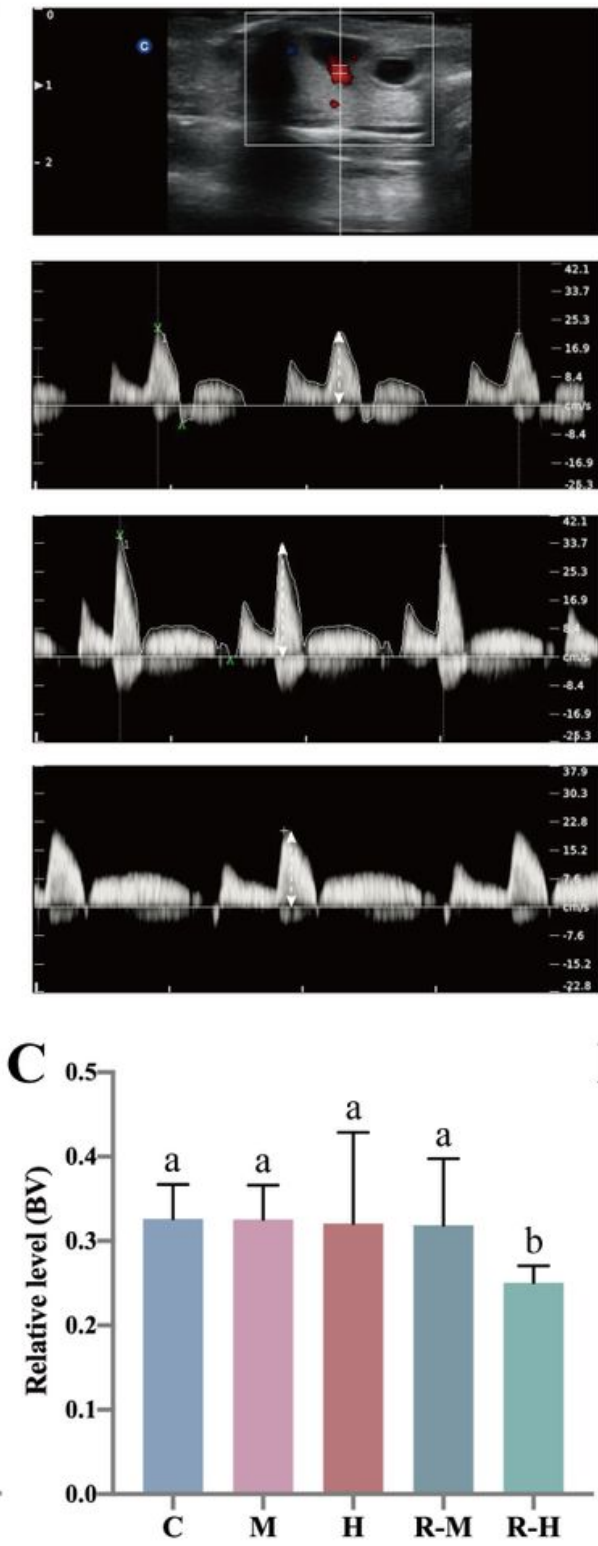

Atrioventricular valve
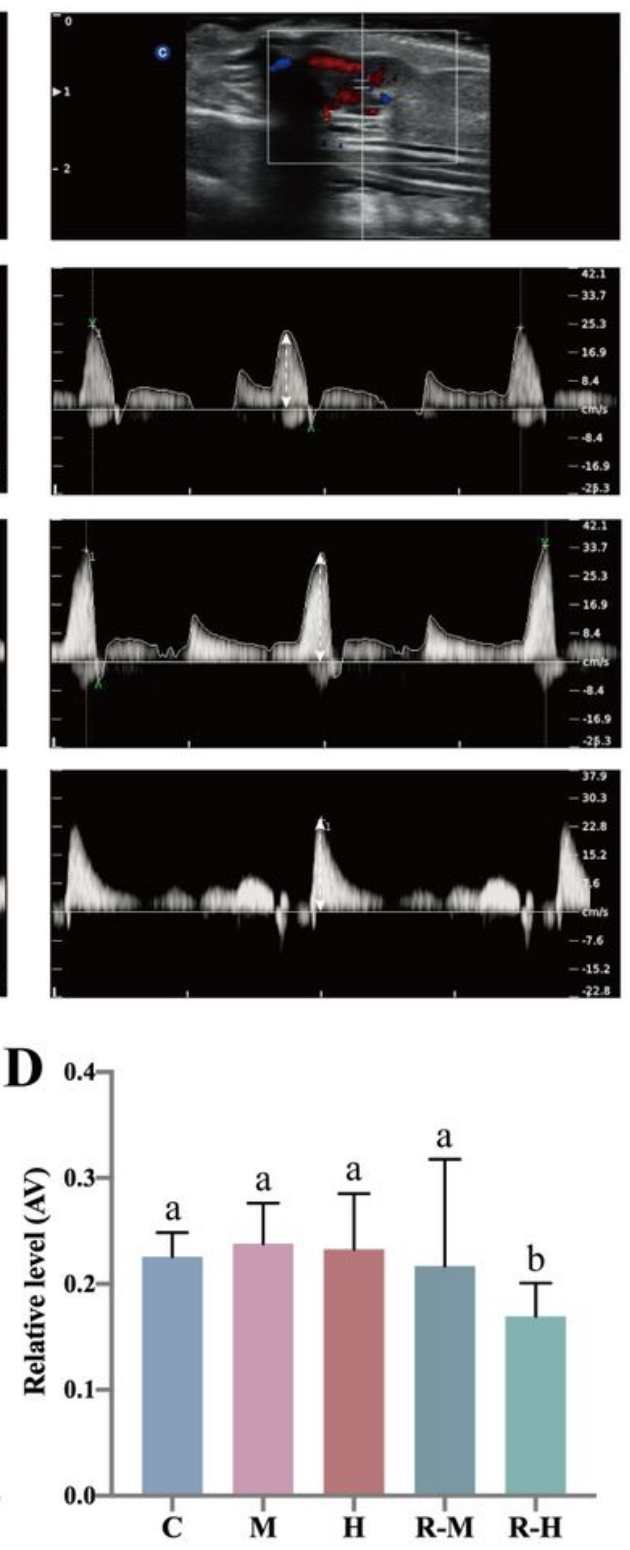

\section{Figure 8}

Ventricular activity, outflow and inflow parameters in A. baerii measured by B-mode and Doppler echocardiography. A and B: Ventricular end-diastolic area (VEDA) and ventricular end-systolic area (VESA), respectively, evaluated by area (mm2); C: Atrioventricular annulus diameter; D: Heart rate. E: Pl; F: SV; G: CO; H: VET. All echocardiographic results were standardized by body weight. Different lowercase letters indicate significant differences between groups $(P<0.05)$.

\section{Supplementary Files}

This is a list of supplementary files associated with this preprint. Click to download.

- SupplementaryVideo.1.avi 
- SupplementaryVideo.2.avi

- Supplementarytable1.docx 